\title{
Multiple new-particle growth pathways observed at the US DOE Southern Great Plains field site
}

\author{
Anna L. Hodshire ${ }^{1}$, Michael J. Lawler, ${ }^{2, a}$, Jun Zhao ${ }^{3, b}$, John Ortega $^{2}$, Coty Jen ${ }^{3, c}$, Taina Yli-Juuti ${ }^{4}$, Jared F. Brewer ${ }^{1}$, \\ Jack K. Kodros ${ }^{1}$, Kelley C. Barsanti ${ }^{5, d}$, Dave R. Hanson ${ }^{6}$, Peter H. McMurry ${ }^{3}$, James N. Smith ${ }^{7}$, and Jeffery R. Pierce ${ }^{1}$ \\ ${ }^{1}$ Department of Atmospheric Science, Colorado State University, Fort Collins, 80523, USA \\ ${ }^{2}$ Atmospheric Chemistry Observations \& Modeling, National Center for Atmospheric Research, Boulder, 80305, USA \\ ${ }^{3}$ Department of Mechanical Engineering, University of Minnesota-Twin Cities, Minneapolis, 55455, USA \\ ${ }^{4}$ Department of Applied Physics, University of Eastern Finland, Kupio, 70211, Finland \\ ${ }^{5}$ Department of Civil and Environmental Engineering, Portland State University, Portland, 97201, USA \\ ${ }^{6}$ Department of Chemistry, Augsburg College, Minneapolis, 55454, USA \\ ${ }^{7}$ Department of Chemistry, University of California, Irvine, 92697-2025, USA \\ ${ }^{a}$ now at: Department of Chemistry, University of California, Irvine, 92697-2025, USA \\ ${ }^{b}$ now at: School of Atmospheric Sciences, Sun Yat-sen University, Guangzhou, 510275, China \\ c now at: Environmental Science, Policy, and Management, University of California, Berkeley, 94720-3114, USA \\ ${ }^{d}$ now at: Chemical and Environmental Engineering, University of California, Riverside, 92521, USA
}

Correspondence to: Anna L. Hodshire (hodshire@rams.colostate.edu)

Received: 19 February 2016 - Published in Atmos. Chem. Phys. Discuss.: 31 March 2016

Revised: 8 July 2016 - Accepted: 9 July 2016 - Published: 28 July 2016

\begin{abstract}
New-particle formation (NPF) is a significant source of aerosol particles into the atmosphere. However, these particles are initially too small to have climatic importance and must grow, primarily through net uptake of lowvolatility species, from diameters $\sim 1$ to $30-100 \mathrm{~nm}$ in order to potentially impact climate. There are currently uncertainties in the physical and chemical processes associated with the growth of these freshly formed particles that lead to uncertainties in aerosol-climate modeling. Four main pathways for new-particle growth have been identified: condensation of sulfuric-acid vapor (and associated bases when available), condensation of organic vapors, uptake of organic acids through acid-base chemistry in the particle phase, and accretion of organic molecules in the particle phase to create a lower-volatility compound that then contributes to the aerosol mass. The relative importance of each pathway is uncertain and is the focus of this work.

The 2013 New Particle Formation Study (NPFS) measurement campaign took place at the DOE Southern Great Plains (SGP) facility in Lamont, Oklahoma, during spring 2013. Measured gas- and particle-phase compositions during these new-particle growth events suggest three distinct
\end{abstract}

growth pathways: (1) growth by primarily organics, (2) growth by primarily sulfuric acid and ammonia, and (3) growth by primarily sulfuric acid and associated bases and organics. To supplement the measurements, we used the particle growth model MABNAG (Model for Acid-Base chemistry in NAnoparticle Growth) to gain further insight into the growth processes on these 3 days at SGP. MABNAG simulates growth from (1) sulfuric-acid condensation (and subsequent salt formation with ammonia or amines), (2) nearirreversible condensation from nonreactive extremely lowvolatility organic compounds (ELVOCs), and (3) organicacid condensation and subsequent salt formation with ammonia or amines. MABNAG is able to corroborate the observed differing growth pathways, while also predicting that ELVOCs contribute more to growth than organic salt formation. However, most MABNAG model simulations tend to underpredict the observed growth rates between 10 and $20 \mathrm{~nm}$ in diameter; this underprediction may come from neglecting the contributions to growth from semi-to-lowvolatility species or accretion reactions. Our results suggest that in addition to sulfuric acid, ELVOCs are also very important for growth in this rural setting. We discuss the limita- 
tions of our study that arise from not accounting for semiand low-volatility organics, as well as nitrogen-containing species beyond ammonia and amines in the model. Quantitatively understanding the overall budget, evolution, and thermodynamic properties of lower-volatility organics in the atmosphere will be essential for improving global aerosol models.

\section{Introduction}

Atmospheric aerosols can affect climate directly, through the absorption and scattering of solar radiation (Rosenfeld et al., 2008; Clement et al., 2009), and indirectly, by modifying cloud properties (Charlson et al., 1992). Both of these effects depend on aerosol particle size, with particles with diameters larger than $50-100 \mathrm{~nm}$ dominating the effects. Larger particles scatter and absorb radiation more efficiently than smaller particles (Seinfeld and Pandis, 2006), and particles with diameters larger than $50-100 \mathrm{~nm}$ have the potential to act as cloud condensation nuclei (CCN; a full list of all abbreviations used in the paper is listed in Appendix A) (e.g., Seinfeld and Pandis, 2006). CCN number and activity are instrumental in determining cloud properties, including precipitation and albedo (Rosenfeld et al., 2008; Forster et al., 2007). The predictions of these aerosol impacts on climate remain amongst the largest uncertainties in climate models (Boucher et al., 2013). Thus, in order to better constrain the climate effects of aerosols, atmospheric particle size distributions must be accurately modeled.

The majority of atmospheric aerosols originate from photochemically driven new-particle formation (NPF) (e.g., Spracklen et al., 2008; Pierce and Adams, 2009). NPF is regularly observed to occur throughout the troposphere (e.g., Kulmala et al., 2004; Kuang et al., 2010). We distinguish between nucleation and NPF as follows: nucleation is the formation of stable particles $\sim 1 \mathrm{~nm}$ in diameter from gas-phase sulfuric-acid molecules and stabilizing vapors that could include water, ammonia, amines, diamines, and oxidized organic molecules (e.g., Kirkby et al., 2011; Chen et al., 2012; Almeida et al., 2013; Riccobono et al., 2014; Jen et al., 2016). NPF, however, includes the growth of these stable nuclei to sizes frequently observed in the atmosphere (larger than 3-10 nm). In order to grow to climate-relevant sizes, new particles must grow through uptake of vapors while avoiding being lost to coagulation by larger particles. This competition between growth and coagulational scavenging depends primarily on initial and final particle size, growth rate, and the concentration of pre-existing aerosols (Kerminen et al., 2004; Pierce et al., 2007; Kuang et al., 2010; Westervelt et al., 2013, 2014). Large impacts of NPF on CCN are most favorable under conditions of fast particle growth rates and low pre-existing aerosol concentrations (small coagulation sinks). Thus, it is important to understand both particle growth and the time-evolving particle size distributions in order to model the resulting CCN concentrations from newparticle events accurately. In this work, we focus upon the growth of particles from these NPF events.

Particle growth from NPF events is chemically complex and poorly understood. Irreversible condensation of sulfuricacid vapor (produced through gas-phase oxidation of $\mathrm{SO}_{2}$ by the hydroxyl radical) is known to be a major contributor to growth. The effective equilibrium vapor pressure of sulfuric acid in the presence of tropospheric water vapor is negligible compared to ambient sulfuric-acid concentrations (Marti et al., 1997), and sulfuric acid readily condenses to the smallest stable particles, often forming inorganic salts with associated bases when available. However, observed particle growth often exceeds that which can be explained by the condensation of sulfuric acid alone (Weber et al., 1997; Stoltzenburg et al., 2005; Riipinen et al., 2007; Iida et al., 2008; Kuang et al., 2010; Smith et al., 2010; Pierce et al., 2012). These and other studies have shown that the uptake of lowvolatility organic vapors is also important and even explains the majority of growth for some regions (e.g., Smith and Rathbone, 2008; Kuang et al., 2009; Riipinen et al., 2011; Bzdek et al., 2014; Xu et al., 2015). Growth by organics may involve a large number of species and multiple growth pathways (Riipinen et al., 2012). We propose that particle growth rate can be modeled as the sum of the following processes: irreversible condensation of sulfuric acid $\left(\mathrm{GR}_{\mathrm{H}_{2} \mathrm{SO}_{4}}\right)$, reversible or nearly irreversible condensation of semivolatile or low-volatility organic compounds ( $\left.\mathrm{GR}_{\text {org cond }}\right)$, uptake of organic acids through acid-base chemistry in the particle phase ( $\left.\mathrm{GR}_{\text {acid-base }}\right)$, and growth from the accretion of two or more organic molecules in the particle phase to form a lowervolatility compound that can then contribute to aerosol mass $\left(\mathrm{GR}_{\text {accret }}\right)$ :

$\mathrm{GR}=\mathrm{GR}_{\mathrm{H}_{2} \mathrm{SO}_{4}}+\mathrm{GR}_{\text {org cond }}+\mathrm{GR}_{\text {acid-base }}+\mathrm{GR}_{\text {accret }}$.

The contribution of atmospheric vapors to observed growth rates through condensation of these organic vapors (without reactions in the particle phase) depends heavily upon the volatility of the organics in the gas phase. It is estimated that the equilibrium vapor pressure required for near-irreversible condensation of vapors onto nanoparticles (defined here to be aerosol particles with an ambient diameter less than $50 \mathrm{~nm}$ ) must be around $10^{-7} \mathrm{~Pa}\left(\sim 10^{-12} \mathrm{~atm}\right)$ or less, corresponding to a saturation concentration of $10^{-4}-10^{-3} \mu \mathrm{g} \mathrm{m}^{-3}$ (Donahue et al., 2011; Pierce et al., 2011).

The presence of essentially nonvolatile organic vapors in the atmosphere, referred to here as extremely low-volatility organic compounds (ELVOCs), defined to have saturation concentrations of around $10^{-4} \mathrm{\mu g} \mathrm{m}^{-3}$ or less (Murphy et al., 2014), have been detected in both laboratory and ambient measurements (Ehn et al., 2012; Zhao et al., 2013, Jokinen et al., 2015). Ehn et al. (2014) proposed a possible chemical pathway in which large atmospheric organic parent molecules (e.g., terpenes) undergo initial oxidation to 
form peroxy radicals followed by rapid autoxidation (self reaction), creating highly oxygenated, yet still large (e.g., 10 carbons), molecules. This pathway has since been confirmed by Jokinen et al. (2014) and Rissanen et al. (2014). Jokinen et al. (2015) determined ELVOC yields from five major biological volatile organic compound (BVOC) species from both ozonolysis and $\mathrm{OH}$ oxidation, including isoprene and four monoterpenes (limonene, alpha-pinene, myrcene, and beta-pinene). The ELVOC yield for isoprene from the two oxidation pathways is low (0.01 and $0.03 \%$, respectively); however, since isoprene emissions are the highest among all non-methane BVOCs (Guenther et al., 2006), these pathways could contribute an appreciable amount of ELVOCs in high isoprene-emitting regions (e.g., Yu et al., 2014). The monoterpenes have much higher ELVOC yields, ranging from 0.12 to $5.3 \%$, depending on both the monoterpene structure and oxidation pathway. Subsequent global aerosol simulations have indicated that the ELVOCs produced from the observed monoterpene yields increased NPF and growth globally, which in turn increased total number concentrations across most of the continental regions and moderately increased the number of CCN (Jokinen et al., 2015).

Ammonia can form inorganic salts in atmospheric particles with sulfuric acid and nitric acid (Jaeschke et al., 1998; Seinfeld and Pandis, 1998); these reactions shift the equilibrium of ammonia (the partitioning species) to the particle phase, as the inorganic salts are lower in volatility than their individual constituents (Pankow, 2003; Pinder et al., 2007). Amines (nitrogen-containing bases with at least one carbon) and organic acids also are observed in growing new atmospheric particles (e.g., Mäkelä et al., 2001; Smith and Rathbone, 2008; Smith et al., 2010; Wang et al., 2010; Tao et al., 2015). Since the vapor pressures of these compounds are higher than is favorable for contributing to new-particle growth by nonreactive condensation alone, the formation of organic salts (formed from organic acids reacting with either amines or ammonia) has been suggested as a potential mechanism for reducing the volatility of these compounds (Barsanti et al., 2009). The presence of these organic-acid and base species in the particle phase depends on the thermodynamic properties of these species (volatility and $\mathrm{pKa}$ ) (Barsanti et al., 2009) as well as the amount of sulfuric acid, which will preferentially react with bases.

Accretion products are formed from a large variety of reactions, through which organic molecules may contribute to particle mass by reactions between organic molecules that reduce the volatility of the parent molecules (Barsanti and Pankow, 2004; Pun and Seigneur, 2007). Assessing the tendency of atmospheric molecules to undergo accretion reactions via thermodynamic considerations showed that glyoxal and methylglyoxal and acetic, malic, maleic, pinic, and likely other similar mono- and dicarboxylic acids have the thermodynamic potential to contribute significantly to particle growth under the right kinetic conditions (Barsanti and Pankow, 2004, 2005, 2006). Matsunaga et al. (2005) found that small multifunctional compounds (e.g., methylglyoxal) in the ambient atmosphere had a much higher particle-phase affinity than predicted by their Henry's law constants; they proposed oligomerization as a possible pathway. Several laboratory studies have confirmed the presence of accretion products in secondary organic aerosols (SOA) formed from a variety of precursor species (Limbeck et al., 2003; Tolocka et al., 2004; Heaton et al., 2007; Wang et al., 2010). On a mass basis, polymers and oligomers have been found to account for up to $50 \%$ of the SOA formed from ozonolysis (Gao et al., 2004; Kalberer et al., 2004; Hall and Johnston et al., 2011). Wang et al. (2010) directly observed oligomers from glyoxal reactions in growing particles from 4 to $20 \mathrm{~nm}$ in diameter, indicating that accretion products have the potential to contribute to new-particle growth. While there are studies showing that accretion could be an important process for particle growth, there are still many uncertainties associated with it.

Despite the growing body of evidence for multiple growth pathways for new-particle growth, current global and regional model studies of aerosol impacts focus on growth through the condensation of vapors only, generally sulfuric acid and lumped organics (e.g., Yu et al., 2011; D'Andrea et al., 2013; Jokinen et al., 2015; Scott et al., 2015). Often, global and regional models with online aerosol microphysics have made simplified assumptions about SOA yields and the size-dependent uptake of organic vapors to particles. Many microphysics models assume fixed SOA yields (e.g., Pierce et al., 2009; Spracklen et al., 2010, 2011; Westervelt et al., 2013), as size- and volatility-resolved vapor condensation/evaporation is a computationally burdensome system; others explicitly include volatility-dependent yields (e.g., Zaveri et al., 2008; Yu et al., 2011). The fixed-yield models either treat SOA as ideally semi-volatile, with the assumption that organic vapors reach instantaneous equilibrium with the aerosol and condense proportionally to the pre-existing particle mass distribution, or the models assume that the SOA is effectively nonvolatile and condenses proportionally to the pre-existing Fuchs-corrected surface area (Pierce et al., 2011; Riipinen et al., 2011; Zhang et al., 2012a).

Generally, regional and global models do not account explicitly for the possible particle-phase reactions (organic acid-base chemistry and oligomerization) with some exceptions (e.g., Carlton et al., 2010). To our knowledge, no regional or global modeling study has investigated the role of these particle-phase reactions on new-particle growth. The studies discussed above are simply attempting to account for all growth via traditional nonreactive gas-phase condensation. However, there are several process-based box models that implicitly or explicitly simulate particle-phase processes in addition to condensation and nonreactive partitioning, including the oligomer formation framework of Pun and Seigneur (2007) and Ervens et al. (2010); the kinetic modeling framework of Pöschl et al. (2007), extended by Shiraiwa and co-workers to build multi-layer kinetic models of 
gas-aerosol interactions (Shiraiwa et al., 2009, 2010, 2012); and the Model for Acid-Base chemistry in NAnoparticle Growth (MABNAG; Yli-Juuti et al., 2013), a single-particle growth model that simulates particle-phase acid-base reactions as well as condensation/evaporation. These detailed, process-based aerosol models may be used to determine the relative contributions of the various potential growth pathways $\left(\mathrm{GR}_{\mathrm{H}_{2} \mathrm{SO}_{4}}, \mathrm{GR}_{\text {org cond }}, \mathrm{GR}_{\text {acid-base }}, \mathrm{GR}_{\text {accret }}\right)$ but to our knowledge have not been used extensively in conjunction with detailed measurements of growth events. Ultimately, well-tested and measurement-informed process-based models should be used in the future to create next-generation particle-growth schemes for more realistic global and regional aerosol models.

In this study, we seek to understand the species and mechanisms that drove the growth of new particles observed during the Southern Great Plains (SGP) New Particle Formation Study (NPFS) in April-May 2013 in Oklahoma, USA. We attempt to find closure in particle growth rates and particle composition between a state-of-the-art process-based growth model (MABNAG) and detailed measurements of particle growth, particle composition, and gas-phase species. We consider $\mathrm{GR}_{\mathrm{H}_{2} \mathrm{SO}_{4}}, \mathrm{GR}_{\text {org cond }}$, and $\mathrm{GR}_{\text {acid-base }}$. We do not consider $\mathrm{GR}_{\text {accret }}$ as we do not have sufficient measurements to constrain these rates. Through this closure process, we provide estimates of the dominant species and mechanisms for three specific growth events observed during the study. Section 2 provides an overview of our measurement and modeling methods. Section 3 closely examines three NPF events observed during the NPFS at SGP and compares these events to modeling results using MABNAG. Conclusions and future work are discussed in Sect. 4.

\section{Methods}

The SGP NPFS took place from 13 April to 24 May 2013 (http://www.arm.gov/campaigns/sgp2013npfs). The primary objectives of the campaign were to study the formation and evolution of aerosols and the impacts of the newly formed particles on cloud processes. The majority of the measurements (and all of those used in this work) took place at the US Department of Energy (DOE) Atmospheric Radiation Measurement (ARM) SGP Central Facility in the Guest Instrument Facility. The site is representative of the large Great Plains region, with agricultural activities, such as cattle and pig husbandry, as well as oil and gas extraction. To our knowledge, the nucleation and growth in the Great Plains region has not been studied in detail. For more information on the site and campaign, visit the DOE and campaign report websites (http://www.arm.gov/sites/sgp and http://www.arm. gov/campaigns/sgp2013npfs). Thirteen new-particle formation events were observed during the NPFS. In this paper, we focus on three new-particle formation events that occurred on 19 April, 9 May, and 11 May; these were the days when NPF was observed and all the available equipment was operating properly. Figure 1 shows the observed size distributions and derived back trajectories from the HYbrid Single-Particle Lagrangian Integrated Trajectory (HYSPLIT) model (Draxler and Rolph, 2012; Rolph, 2012) for these 3 days. These data will be described in detail later.

\subsection{Measurements}

During the 6-week campaign, 13 new-particle formation events were observed at Lamont by a battery of three scanning mobility particle sizers (SMPSs) operated in parallel. They included the DEG SMPS (a TSI 3085 Nano DMA operated with a laboratory prototype laminar flow diethylene glycol condensation particle counter detector; Jiang et al. (2011); 1.9-13.6 nm mobility diameter), a nano SMPS (a TSI 3085 nano DMA operated with a TSI 3025A laminar flow ultrafine butanol CPC detector; $2.8-47 \mathrm{~nm}$ mobility diameter), and a conventional SMPS (a home-built long column DMA with dimensions similar to the TSI 3071 with a TSI 3760 CPC detector; $23-528 \mathrm{~nm}$ mobility diameter). For all systems, filtered ambient air was used for the DMA sheath air, without adjusting the water vapor partial pressure. Therefore, the relative humidity was close to ambient relative humidity, and particle water content was close to that in the atmosphere.

Nanoparticle composition data were collected using the Thermal Decomposition Chemical Ionization Mass Spectrometer (TDCIMS) (Voisin et al., 2003; Smith et al., 2004). For the observations reported here, we used the recently developed time-of-flight mass spectrometer version of the instrument (TOF-TDCIMS) (Lawler et al., 2014). The TDCIMS measures the molecular composition of size-selected atmospheric nanoparticles in near real time. It performs this measurement by first charging and size-selecting nanoparticles using unipolar chargers and differential mobility analyzers, respectively. Charged, size-selected particles are collected by electrostatic precipitation onto a platinum filament for approximately $30 \mathrm{~min}$. Following this, the filament is moved into the ion source of a chemical ionization mass spectrometer and undergoes a current ramp to reach an estimated maximum temperature of $600^{\circ} \mathrm{C}$. This heating thermally desorbs and/or decomposes the sample to produce gasphase analyses. Two different chemical ionization reagents are used to detect the chemical species desorbed from the sample: $\mathrm{H}_{3} \mathrm{O}^{+}\left(\mathrm{H}_{2} \mathrm{O}\right)_{n}(n=0-3)$, hereafter referred to as "positive ion chemistry", detects base compounds such as ammonia and amines as well as carbonyl-containing compounds and some alcohols; $\mathrm{O}_{2}^{-}\left(\mathrm{H}_{3} \mathrm{O}\right)_{n}(n=0-3)$, hereafter referred to as "negative ion chemistry", detects organic and inorganic compounds with acid groups, as well as other oxygenated compounds with high electron affinities. During the campaign, the instrument cycled roughly hourly between positive and negative ion chemistry. We classify the detected ions into the following categories: ammonia, amine/amide, 

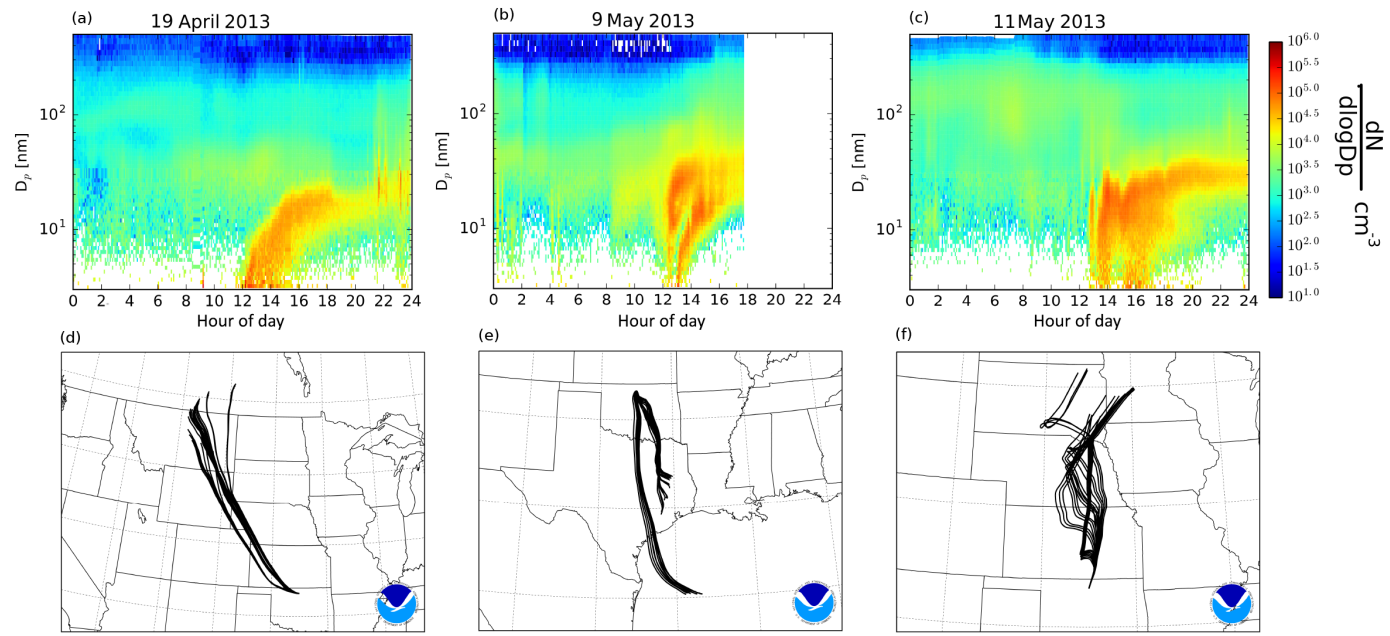

Figure 1. (a-c) The growth events for 19 April, 9 May, and 11 May 2013, as captured by a scanning mobility particle sizer at SGP. Each plot shares the same color bar. (d-f) The associated $48 \mathrm{hr}$ HYSPLIT back trajectories for each day as calculated using the NOAA HYSPLIT Model with NAM meteorological data, initialized at $250 \mathrm{~m}$ a.g.l.

organics with sulfur, organics with nitrogen, organics without sulfur or nitrogen, sulfate, and nitrates that are either oxidized (no carbons) or inorganic (see Figs. 2, 4, and 6c-d). At the present time, we have not identified marker compounds for the condensation of ELVOCs; however, a prior laboratory study has shown that the detection of organic acids in nanoparticles correlates with the early growth of nanoparticles from the oxidation of $\alpha$-pinene (Winkler et al., 2012). We are also unable to distinguish between the oxidized nitrates and the inorganic nitrates; thus we have grouped these ions together (the nitrate (ox/inorg) category in Figs. 2, 4, and $6 \mathrm{c}-\mathrm{d})$.

Ambient gas-phase sulfuric acid (both monomers and dimers), malonic acid, and oxalic acid were measured with the cluster CIMS using nitrate core ion (present primarily as dimer, $\mathrm{HNO}_{3} \cdot \mathrm{NO}_{3}^{-}$) as the chemical ionization reagent ion (Zhao et al., 2010). Sulfuric acid, malonic acid, and oxalic acid were detected at $m / z 160,166$, and 152 respectively (the molecules clustered with a nitrate ion). The cluster CIMS measures those acids with unit mass resolution. The detection of sulfuric acid in the CIMS has been quantified and calibrated, and the uncertainties for the concentrations of the monomers and dimers of sulfuric acid are estimated to be factors of 1.5 and 3, respectively (Chen et al., 2013). However, the detection of oxalic acid and, to a much lesser extent, malonic acid may not be as efficient as sulfuric acid due to gas-phase proton affinities of the organic acids compared to that of nitric acid. A calibration comparison with a different cluster CIMS using acetate $\left(\mathrm{CH}_{3} \mathrm{CO}_{2} \mathrm{H}^{\cdot} \mathrm{CH}_{3} \mathrm{CO}_{2}^{-}\right)$as the reagent ion (Jen et al., 2015) showed up to 2 orders of magnitude higher inferred oxalic-acid concentration and approximately similar malonic concentrations as the nitrate cluster CIMS. Therefore, the estimated systematic uncertainty in the oxalic-acid concentration measured via nitrate chemical ion- ization is approximately up to a factor 100 times lower than reported, indicating that the actual concentration could be up to 100 times higher than observed. We explore the sensitivity of the model to these organic-acid uncertainties in this paper.

Ambient gas-phase amines and ammonia concentrations were measured using the Ambient pressure Proton transfer Mass Spectrometer (AmPMS) (Hanson et al., 2011; Freshour et al., 2014), a quadrupole instrument (unit mass resolution) with high sensitivities for ammonia and amines. Signals at the protonated parent masses for methylamine, dimethylamine (DMA), and trimethylamine (TMA) (C1-C3 amines) were assigned with confidence; also detected was a suite of larger alkylamines with four to seven carbons (C4-C7). Less is known about the speciation of these larger amines, as ambient measurements of amines larger than $\mathrm{C} 3$ are not often made (e.g., Ge et al., 2011). Contribution of amides to the signals at the masses of the larger amines may also be significant; as such, no structure information was assigned to the C4-C7 amines, as many isomers are possible. Uncertainties in the AmPMS data for this campaign are discussed further in Freshour et al. (2014) and are estimated to be $+150 /-60 \%$ overall.

A proton transfer reaction mass spectrometer (PTR-MS) based on the design of Hanson et al. (2011) was operated unattended during the campaign and was set to measure a suite of volatile organic compounds (VOCs), including isoprene and monoterpenes. However, only one calibration was done for the PTR-MS on 18 May, 35 days into the campaign, and during processing, unexplainable spikes were seen in the data at irregular intervals. Further, monoterpene mixing ratios were nearly always unreasonably high (often ranging between 10 and $100 \mathrm{ppbv}$ ). For comparison, a field site in Manitou, Colorado, comprised of a ponderosa pine stand, had maximum monoterpene mixing ratios of $1-2$ ppbv dur- 
ing the mid-summer (Ortega et al., 2014), and we expect the monoterpene emissions near the SGP (with few trees) site in April and May to be lower than the forested Manitou site in summer. We thus lack confidence overall in the VOC data obtained by the PTR-MS, so we use an alternative method for estimating monoterpene concentrations, which is described below.

\subsection{ELVOC estimate}

Rather than using the PTR-MS for VOC data, which suffered from calibration issues, we estimate monoterpene emissions and concentrations using the Model of Emissions of Gases and Aerosols from Nature version 2.1 (MEGAN2.1) (Guenther et al., 2006, 2012; Sindelarova et al., 2014) in the Goddard Earth Observing System chemical-transport model (GEOS-Chem; http://geos-chem.org). We ran MEGAN2.1 in GEOS-Chem at a $2 \times 2.5^{\circ}$ resolution to estimate monoterpene emissions rates (monoterpenes are not tracked as prognostic species in these GEOS-Chem simulations). The specific monoterpenes estimated are $\alpha$-pinene, $\beta$-pinene, limonene, sabinene, myrcene, 3-carene, ocimene, and the lumped sum of other monoterpenes (see Guenther et al., 2012 for a complete list). These GEOS-Chem simulations use GEOSFP meteorological fields generated by the Goddard Modeling and Assimilation Office (GMAO, http://gmao.gsfc. nasa.gov/) and include biogenic emission-factor updates to MEGAN2.1 based on Guenther et al. (2012) and Sindelarova et al. (2014). For a discussion on the uncertainties associated with emissions from MEGAN2.1, see Guenther et al. (2012). We estimate pseudo-steady-state monoterpene concentrations by assuming that the emitted monoterpenes are well mixed up to the boundary-layer (BL) height measured at SGP and that emissions are balanced by chemical loss by ozonolysis. (The BL height measurements were obtained by the ARM value-added product radiosonde (PBLHTSONDE) at the SGP Central Facility.) For ozonolysis, we used a rate constant, $k$, of $8.1 \times 10^{-17} \mathrm{~cm}^{3}$ molecule ${ }^{-1} \mathrm{~s}^{-1}$ for all monoterpenes, from IUPAC (http://www.iupac.org). For the ozone concentrations, we used hourly ozone monitor measurements from the closest EPA monitoring site, at Dewey, OK, which is 120 miles $(\sim 190 \mathrm{~km}) \mathrm{SW}$ of the SGP site. The uncertainty in ozone concentration due to the distance between measurements is a source of potential error in our monoterpene concentration calculation; however, since we expect ozone concentrations to be relatively homogeneous regionally, we expect other errors (such as ELVOC yields) to be more significant sources of ELVOC uncertainty.

We estimate the gas-phase ELVOC from the oxidation of the monoterpene (MT) concentrations obtained from MEGAN, assuming a pseudo-steady state between its chemical production and loss by irreversible condensation and neglecting dry deposition as the condensation sink timescales are faster than the dry-deposition timescales (Pierce and Adams, 2009):
$[\mathrm{ELVOC}]=\frac{0.03 k\left[\mathrm{O}_{3}\right][\mathrm{MT}]}{\mathrm{CS}}$,

where CS is the condensation sink, calculated from the SMPS aerosol size-distribution measurements. We note that the SMPS measurements only go up to $\sim 650 \mathrm{~nm}$ mobility diameter, so the condensation sink calculated represents a lower limit on the actual condensation sink. The prefactor, 0.03 , is the ELVOC molar yield from the $\alpha$-pinene + ozone reaction found in Jokinen et al. (2015). $\alpha$-Pinene represents $\sim 30 \%$ of the MEGAN-estimated monoterpenes present at SGP during the campaign, which is the largest fraction by any of our estimated monoterpene species. Thus, we assume the $\alpha$-pinene yield to be representative of all of the monoterpenes; in reality, some monoterpene species have higher or lower yields. We do not know the ELVOC yield from oxidation processes for all monoterpene species; thus, this estimate of the ELVOC concentration should be taken as one possible outcome of monoterpene oxidation. We also acknowledge that our modeled monoterpene concentrations depend on the modeled ozone concentrations, whereas we used the measured ozone concentrations to determine the ELVOC yield. The errors in this assumption are likely small compared to our uncertainties in the ELVOC yield.

\subsubsection{Model description}

MABNAG has been developed by Yli-Juuti et al. (2013) to simulate the growth and composition of a single particle resulting from both condensation of low-volatility vapors and acid-base reactions in the particle phase. The version of MABNAG used for this study accepts as inputs the gas-phase concentrations and properties of water, sulfuric acid, a representative organic acid, ammonia, a representative amine, and a representative nonreactive organic, taken here to be an ELVOC. The organic compounds are represented in MABNAG with the chemical properties (e.g., pKa, molecular mass, equilibrium vapor pressure) of one organic acid, one amine, and one ELVOC; thus, we must make assumptions about the properties of the organic acid, amine, and ELVOC inputs that are representative for the wide ranges of organic-acid, amine, and ELVOC species. MABNAG also requires an initial particle size and composition; for simplicity in this study, the initial particle is formed from 20 molecules of each input species, creating a particle approximately $3 \mathrm{~nm}$ in diameter. The choice of molecules in forming the initial particle has negligible influence on the growth rate and composition in the $10-20 \mathrm{~nm}$ size range. We assume a particle density of $1.5 \mathrm{~g} \mathrm{~cm}^{-3}$ and a surface tension of $0.03 \mathrm{~N} \mathrm{~m}^{-1}$. A sensitivity case using $0.05 \mathrm{~N} \mathrm{~m}^{-1}$ for the surface tension did not affect our results at the particle diameters where we compare to measurements (above $10 \mathrm{~nm}$ ).

The uptake rates of sulfuric acid, the organic acid, and the ELVOC are calculated as gas-phase diffusion-limited mass 
transfer based on their ambient vapor pressures, equilibrium vapor pressures, and gas-phase diffusivities. Water and the bases are assumed to instantly reach equilibrium between the gas and particle phases due to their higher diffusivities and pure-species vapor pressures. Upon uptake, subsequent acid dissociations and base protonations in the particle phase are calculated by the Extended Aerosol Inorganics Model (EAIM) (http://www.aim.env.uea.ac.uk/aim/aim.php, Clegg et al., 1992; Clegg and Seinfeld, 2006a, b; Wexler and Clegg, 2002). It is assumed that the ELVOC does not dissociate in the particle phase. This vapor pressure is low enough that uptake of ELVOCs is essentially irreversible, even at the smallest simulated particle sizes. We do not consider any additional particle-phase reactions beyond the acid-base reactions: this includes possible accretion reactions that could contribute to growth. We have estimated ELVOC concentrations as they have been shown to have a direct oxidation pathway from monoterpene species to ELVOC species (e.g., Jokinen et al., 2015). However, the estimations of the concentrations of semivolatile organic compounds (SVOCs), organics with saturation concentrations of $10^{0}-10^{2} \mu \mathrm{g} \mathrm{m}^{-3}$ (Murphy et al., 2014), and the contribution to growth from oligomerization are much less constrained: one must know how the SVOCs are reversibly partitioning to the full aerosol size distribution (as opposed to irreversible condensation to the condensation sink for ELVOCs), and oligomerization rates and the involved SVOC species are highly uncertain. For these reasons, we will not attempt to estimate the SVOC concentration present at SGP and will neglect oligomerization reactions in this work. SVOCs may also directly contribute to particle growth through condensation, as can low-volatility organic compounds (LVOCs), organics with saturation concentrations of $10^{-3}-10^{-1} \mu \mathrm{g} \mathrm{m}^{-3}$ (Murphy et al., 2014). The condensation of SVOCs and LVOCs depends on particle size; the likelihood of irreversible condensation increases with increasing particle size (Pierce et al., 2011). Pierce et al. (2011) estimate that SVOCs and LVOCs can begin contributing to particle growth at diameters as small as $\sim 10$ and $\sim 3 \mathrm{~nm}$, respectively, but there are still considerable uncertainties as to the extent to which LVOCs and SVOCs partition to these smaller particle sizes. Thus, omitting LVOCs, SVOCs, and resultant condensational growth and/or oligomerization reactions from SVOCs that contribute to growth is a limitation of this study and will be discussed further in the conclusions.

MABNAG assumes that species that enter the particle are instantaneously and homogeneously mixed into a liquid particle phase. This ignores potential particle-phase diffusion limitations that can arise from heterogeneous particle phases. SOA has been observed to have solid and semi-solid phases in both the laboratory and the field (Virtanen et al., 2010, 2011). Riipinen et al. (2012) estimated the importance of potential diffusion limitations as a function of size: they argue that diffusion does not limit growth for particles smaller than $20 \mathrm{~nm}$ diameter but is potentially important for particles 20
$50 \mathrm{~nm}$. However, this remains an uncertainty, and we will address this later.

\subsubsection{Model inputs}

Inputs to MABNAG were the gas-phase concentrations from observations or MEGAN-based modeling (Table 1) and chemical properties (Table 2) of water, sulfuric acid, ammonia, an amine, an organic acid, and a nonreactive organic. Relative humidity ( $\mathrm{RH}$ ) is used as a proxy for the water concentration and was obtained from the $60 \mathrm{~m}$ tower data maintained by ARM at the Central Facility. Atmospheric temperature was also obtained from the $60 \mathrm{~m}$ tower data. The SGP measurement data described earlier provide the gas-phase concentrations of sulfuric acid, ammonia, a suite of amines, and two organic acids, malonic and oxalic acid. The nonreactive organic input will be our ELVOC concentration estimate from the MEGAN monoterpene emissions. ELVOCs consist of a large range of high-molecular-weight compounds with currently unknown structures (Ehn et al., 2014). We assume that our representative ELVOC is one of the dominant ELVOC monomer peaks seen in the mass spectra measured by Ehn et al. (2014), $\mathrm{C}_{10} \mathrm{H}_{16} \mathrm{O}_{9}$, molecular weight of $280 \mathrm{~g} \mathrm{~mol}^{-1}$, with the possible structure of three $\mathrm{COOH}$ groups, four $\mathrm{CH}$ groups, three $\mathrm{CH}_{2}$ groups, and three $\mathrm{OH}$ groups. (Chemical structure is required for the UNIFAC activity coefficient calculations in E-AIM in MABNAG.) However, as the vapor pressure of this ELVOC is extremely low (assumed to be $10^{-9} \mathrm{~Pa}$ ), simulations are generally insensitive to ELVOC chemical structure. No direct measurements have been made for the saturation vapor pressure of ELVOCs; we assume a saturation vapor pressure of $\times 10^{-9} \mathrm{~Pa}$ (corresponding to a saturation concentration $\left(C^{*}\right)$ of $1 \times 2 \times 10^{-4} \mu \mathrm{g} \mathrm{m}^{-3}$ at $283 \mathrm{~K}$ ). This vapor pressure is low enough that uptake of ELVOCs is essentially irreversible, even at the smallest simulated particle sizes.

MABNAG currently simulates one amine and one organic acid, so we ran a suite of sensitivity cases to assess the range of atmospheric acid and base conditions that could help explain observed particle growth. For the amine input, we tested the chemical properties of two amines with single amino groups: DMA or TMA. We denote these cases as DMA and TMA. The pKas of these species are 10.7 (DMA) to 9.8 (TMA), so amines within this pKa range are represented in our sensitivity studies. We tested the sensitivity to the amine concentration input by using the sum of the light amines only (methylamine, DMA, and TMA only; denoted as Lam) or the sum of all the amines measured (including the C4-C7 amines but excluding the diamines; denoted as Tam) as the input. For the Lam cases, we used the chemical properties of DMA or TMA (denoted DMA_Lam and TMA_Lam, respectively). We assumed the larger amines, which made up over $50 \%$ of the total amines (by mass), have a lower $\mathrm{pKa}$ than the light amines and therefore use properties similar to that of TMA for the Tam cases (denoted 
Table 1. Gas-phase concentration and temperature inputs to MABNAG for each day.

\begin{tabular}{|c|c|c|c|c|c|c|c|}
\hline Day & $\begin{array}{l}T \\
(\mathrm{C})\end{array}$ & RH (\%) & $\begin{array}{l}\text { Sulfuric acid } \\
\left(\mathrm{cm}^{-3}\right)\end{array}$ & $\begin{array}{l}\text { Organic acid: } \\
\text { mal+ox/ } \\
\text { mal+10ox/ } \\
\text { mal }+100 o x \\
\left(\mathrm{~cm}^{-3}\right)\end{array}$ & $\begin{array}{l}\text { Ammonia } \\
\left(\mathrm{cm}^{-3}\right)\end{array}$ & $\begin{array}{l}\text { Amine: } \\
\text { light/ } \\
\text { total } \\
\left(\mathrm{cm}^{-3}\right)\end{array}$ & $\begin{array}{l}\text { ELVOC } \\
\left(\mathrm{cm}^{-3}\right)\end{array}$ \\
\hline $4 / 19 / 13$ & 11.6 & 32 & $2.4 \times 10^{6}$ & $\begin{array}{l}1.17 \times 10^{7} / \\
2.17 \times 10^{7} / \\
1.10 \times 10^{8}\end{array}$ & $2.98 \times 10^{10}$ & $\begin{array}{l}2.91 \times 10^{9} / \\
4.8 \times 10^{10}\end{array}$ & $1.22 \times 10^{7}$ \\
\hline $5 / 09 / 13$ & 12.7 & 69 & $1.97 \times 10^{7}$ & $\begin{array}{l}7.15 \times 10^{7} / \\
1.49 \times 10^{8} / \\
9.11 \times 10^{8}\end{array}$ & $8.94 \times 10^{9}$ & $\begin{array}{l}1.01 \times 10^{9} / \\
2.41 \times 10^{10}\end{array}$ & $4.3 \times 10^{6}$ \\
\hline $5 / 11 / 13$ & 16.4 & 36 & $5.3 \times 10^{6}$ & $\begin{array}{l}2.66 \times 10^{7} / \\
6.43 \times 10^{7} / \\
4.14 \times 10^{8}\end{array}$ & $1.11 \times 10^{10}$ & $\begin{array}{l}1.54 \times 10^{9} / \\
1.85 \times 10^{10}\end{array}$ & $4.1 \times 10^{6}$ \\
\hline
\end{tabular}

Table 2. Chemical properties for each species input in MABNAG.

\begin{tabular}{|c|c|c|c|c|c|c|}
\hline Species & $\begin{array}{l}\text { Molar mass } \\
\left(\mathrm{g} \mathrm{mol}^{-1}\right)\end{array}$ & $\mathrm{pKa} 1$ & pKa 2 & $\begin{array}{l}\text { Vapor pressure } \\
\text { of pure com- } \\
\text { pound }(\mathrm{Pa}) \\
\left(\mu \mathrm{g} \mathrm{m}^{-3}\right)\end{array}$ & $\begin{array}{l}\text { Henry's Law } \\
\text { constant } \\
\text { (mol } \\
\mathrm{kg}^{-1} \mathrm{~atm}^{-1} \text { ) }\end{array}$ & $\begin{array}{l}\text { Diffusion } \\
\text { coefficient } \\
\left(\mathrm{m}^{2} \mathrm{~s}^{-1}\right)\end{array}$ \\
\hline Sulfuric acid & 98.1 & -3 & 1.99 & 0 & $\mathrm{n} / \mathrm{a}$ & $9.4 \times 10^{-6}$ \\
\hline Malonic acid & 104.1 & 2.85 & 5.7 & $\begin{array}{l}4 \times 10^{-5} \\
\left(1.8 \times 10^{-5}\right)\end{array}$ & $\mathrm{n} / \mathrm{a}$ & $8.4 \times 10^{-6^{a}}$ \\
\hline Oxalic acid & 90.03 & 1.46 & 4.4 & $\begin{array}{l}4 \times 10^{-3} \\
\left(1.5 \times 10^{-3}\right)\end{array}$ & $\mathrm{n} / \mathrm{a}$ & $8.4 \times 10^{-6^{b}}$ \\
\hline Ammonia & 17.03 & 9.25 & $\mathrm{n} / \mathrm{a}$ & $\mathrm{n} / \mathrm{a}$ & $60.7^{\mathrm{c}}$ & $\mathrm{n} / \mathrm{a}$ \\
\hline DMA & 45.1 & 10.7 & $\mathrm{n} / \mathrm{a}$ & $\mathrm{n} / \mathrm{a}$ & $31.41^{\mathrm{d}}$ & $\mathrm{n} / \mathrm{a}$ \\
\hline TMA & 59.1 & 9.8 & $\mathrm{n} / \mathrm{a}$ & $\mathrm{n} / \mathrm{a}$ & $9.6^{\mathrm{d}}$ & $\mathrm{n} / \mathrm{a}$ \\
\hline ELVOC $^{\mathrm{e}}$ & 280 & $\mathrm{n} / \mathrm{a}$ & $\mathrm{n} / \mathrm{a}$ & $\begin{array}{l}1 \times 10^{-9} \\
\left(1.2 \times 10^{-3}\right)\end{array}$ & $\mathrm{n} / \mathrm{a}$ & $5 \times 10^{-6}$ \\
\hline
\end{tabular}

a Calculated using the Fuller et al., method (Eqs. 11-4.4 in Poling et al., 2014).

b Assumed to be the same as malonic acid.

c Haar and Gallagher (1978).

d http://webbook.nist.gov/chemistry/.

e Assumed properties of the ELVOC species.

TMA_Tam). This prevents the overestimation of the potential contribution of large amines due to salt formation. The assumption that all larger amines behave similarly with low pKas is likely true for alkylamines with a single amino group but does not apply for diamines. Future studies need to examine how diamines react with acids (e.g., dicarboxylic acids to form nylons) and contribute to nanoparticle growth. Regardless, the range of amine pKas and concentrations examined here illustrate the sensitivity of particles to various parameters. For the organic-acid input, we tested using the chemical properties of oxalic or malonic acid, as these were the organic-acid species measured at SGP. These cases are denoted as OX or MAL. We acknowledge that there is a large range of organic acids in the atmosphere, and other monocar- boxylic and dicarboxylic acids have been measured in ambient particles (e.g., Rogge et al., 1993; Sempere et al., 1994; Khwaja et al., 1995; Kawamura et al., 1996; Limbeck and Puxbaum, 1999). However, aerosol data from urban, rural, and remote regions have shown that malonic acid tends to be among the dominant organic-acid species in the particle phase, with oxalic acid as the dominant organic-acid aerosol species at all measurement locations (e.g., Grosjean et al., 1978; Kawamura and Ikushima, 1993; Rogge et al., 1993; Sempere et al., 1994; Kawamura et al., 1995, 1996; Khwaja et al., 1995; Kawamura and Sakaguchi, 1999; Limbeck and Puxbaum et al., 1999; Kerminen et al., 2000; Narukawa et al., 2002; Mochida et al., 2003; Sempere and Kawamura, 2003). Thus, we estimate that the contribution of organic acids pre- 
dicted by MABNAG represents a lower bound of the total contribution of organic acids to particle growth but might be a reasonable estimate.

There is uncertainty in the saturation vapor pressures of organic acids. A review of dicarboxylic acids and complex mixtures compiled by Bilde et al. (2015) shows the best-fit saturation vapor pressure of the subcooled liquid states of malonic and oxalic acid as functions of temperature (Figs. 7 and 8 of the review). As there are variations between different reported measurements at the same temperature, we have selected to use the saturation vapor pressure values for the subcooled liquid states of oxalic and malonic acid obtained from the best-fit functions in Bilde et al. (2015). Additionally, we include a sensitivity case of reducing the saturation vapor pressures by 1 order of magnitude below the values shown in Table 2. This reduction is within the range of uncertainty in Bilde et al. (2015). We denote simulations using the properties of oxalic acid with the saturation vapor pressure reduced by 1 order of magnitude as OX_LoVP; we use similar notation for the malonic-acid cases (MAL_LoVP).

We further performed sensitivity studies for the concentration of oxalic acid. Due to the uncertainty in the oxalic-acid detection efficiency from the cluster CIMS, the real oxalicacid concentration could be up to 100x the reported concentration (Figs. 2, 4, and 6a). Thus, we ran three sets of concentration input tests: the sum of the reported malonic and oxalic acids (denoted as 1ox), the sum of the reported malonic and 10x the oxalic-acid concentration (denoted as 10ox), and the sum of the reported malonic and 100x the oxalic-acid concentrations (denoted as 100ox). Note that since our simulations include the sum of the oxalic-acid and malonic-acid concentrations, the scaling of the oxalic-acid concentrations implicitly also allows for testing uncertainties in malonicacid uncertainties, although we believe these to be smaller (Eisele and Tanner, 1993). Thus, we tested three dimensions of sensitivities for the organic-acid inputs: pKa, vapor pressure, and organic-acid concentrations.

In total, there are 36 sensitivity cases for each day (Tables 4-6). We present the case MAL/10ox/DMA_Lam as the base case for each day, to which other cases will be compared to Figs. $2-4 \mathrm{e}-\mathrm{f}$. The choice of this case is somewhat arbitrary, but it generally gives intermediate results relative to other simulations, as will be shown later. For each case, we set MABNAG to run until the particle reaches $40 \mathrm{~nm}$ in diameter or, if the mean particle growth rate is below $3.3 \mathrm{~nm} \mathrm{~h}^{-1}$, the model will stop after $12 \mathrm{~h}$ of simulated time.

\subsection{Growth-rate calculations}

\subsubsection{Observed growth rate (SMPS)}

We have calculated the observed growth rates between 10 and $20 \mathrm{~nm}$ for each day of our analysis from the SMPS data (Fig. 1a-c). This size range is used since we constrain our analysis of particle composition to the TDCIMS data. Dur- ing the NPFS campaign, the TDCIMS was set to measure at $\sim 40 \mathrm{~nm}$ mode diameter when new-particle formation events were not ongoing. Then, when the onset of a new-particle formation event was detected, the TDCIMS was set to measure smaller particle sizes, around $20 \mathrm{~nm}$ mode diameter, in order to determine what species were in the freshly growing particles. Thus, our growth-rate calculations represent the size range that the TDCIMS measured in during the events of our analysis.

The plots for 9 and 11 May indicate that there could be two separate nucleation events, whereas 19 April shows one event. Similar to 9 and 11 May, the SMPS data for 12 May show what appears to be two nucleation events occurring at the surface where the SMPS collected size distributions. Tethered-balloon flight profiles for 12 May indicate that nucleation potentially occurred aloft. These observations will be described in detail in a paper currently in preparation but are briefly described here: the balloon payload consisted of two portable condensation particle counters (model 3007, TSI, Inc.) operating at different minimum size-cut points, which allowed the vertically resolved measurement of 10 to $20 \mathrm{~nm}$ diameter particle number concentrations, $N_{10-20 \mathrm{~nm}}$. On 12 May, high concentrations of particles in this size range were detected at $600 \mathrm{~m}$ above ground level, exactly coincident with, or slightly prior to, ground-level observations of high concentrations of $N_{10-20 \mathrm{~nm}}$. We hypothesize the following explanation for the "double" nucleation events observed on 9, 11, and 12 May: nucleation and growth begins to occur aloft in the residual layer. Once the mixed-layer depth grows into the residual layer, these new particles (that may have already grown to $\sim 10 \mathrm{~nm}$ ) then mix down and are measured at the surface. This hypothesis is supported by the presence of a high concentration of larger particles $\left(D_{\mathrm{p}}=10\right.$ $30 \mathrm{~nm}$ ) that have already undergone growth at the "beginning" of the first event as measured by the SMPS on 9 and 11 May. Then, the second event, which presumably begins near the surface, shows a high concentration of freshly growing particles (3-5 nm, close to the limit of the SMPS detection) before larger particles appear.

As a result, we decided to calculate the growth rate based only on the second growth event for 9 and 11 May, as the second growth events are likely more representative of our ground-based measurements. There is considerable noise in the SMPS data (Fig. 1a-c), especially for 9 and 11 May, due possibly to the hypothesized mixing down of particles and possible inhomogeneities in the air mass. For this reason, we have calculated the growth rate between 10 and $20 \mathrm{~nm}$ for each using three different methods. The first method, referred to here as the leading-edge method, is adapted from Lehtipalo et al. (2014) and finds the time at which the binned aerosol distribution between 10 and $20 \mathrm{~nm}$ reaches one half of its maximum $\mathrm{d} N / \mathrm{d} \log D_{\mathrm{p}}$ for each bin. A linear fit between the bin's median diameter and the associated time determines the growth rate. The second method, referred to here as the $D_{\mathrm{p}}$-mode method, tracks the change in diameter of 
Table 3. Observed growth-rate ranges between 10 and $20 \mathrm{~nm}$ for each day.

\begin{tabular}{lccc}
\hline Day & $\begin{array}{c}\text { Leading-edge } \\
\text { method }\left(\mathrm{nm} \mathrm{h}^{-1}\right)\end{array}$ & $\begin{array}{c}D_{\mathrm{p}} \text {-mode } \\
\text { method }\left(\mathrm{nm} \mathrm{h}^{-1}\right)\end{array}$ & $\begin{array}{c}\text { Visual method } \\
\left(\mathrm{nm} \mathrm{h}^{-1}\right)\end{array}$ \\
\hline 19 April & 8.8 & 1.6 & 3.3 \\
9 May & 11.3 & 2.4 & 5.0 \\
11 May & 7.5 & 5.6 & 8.3 \\
\hline
\end{tabular}

the maximum $\mathrm{d} N / \operatorname{dog} D_{\mathrm{p}}$ of the aerosol size distribution between 10 and $20 \mathrm{~nm}$; a linear fit between the diameters and time determines the growth rate. When plotted against the size distribution (see Supplement, Figs. S1-S3), it is seen that the leading-edge and $D_{\mathrm{p}}$-mode method both do not always track the growing size distribution well. For this reason, we have included a third method, which we call the visual method, in which we have made a linear growth rate between 10 and $20 \mathrm{~nm}$ for each day based upon visual inspection of the size distribution (see Supplement, Figs. S1-S3), using Eq. (3):

$\mathrm{GR}_{\mathrm{obs}}=\frac{\mathrm{d} D_{\mathrm{p}}}{\mathrm{d} t} \cong \frac{\Delta D_{\mathrm{p}}}{\Delta t}$.

These three methods provide a range of growth rates (Table 3) for the particles between 10 and $20 \mathrm{~nm}$; the specific results for each day will be discussed in Sect. 3. We do not attempt to provide uncertainty estimates for each method due to the overall noise in the data. Instead, we present the ranges of calculated growth rates as a possible range of the actual growth rates. On 9 and 11 May there tend to be higher growth rates: this could be from the influence of the continued mixing down from nucleation aloft and not actually representative of the growth rates of the particles forming near the surface.

\subsubsection{MABNAG growth rate}

MABNAG provides the wet diameter as a function of time: we calculated the rate of change of these diameters using Eq. (3) to get the modeled growth rate. Growth rates in MABNAG generally increase with size due to the reduction of the Kelvin effect with size (gas-phase concentrations are held fixed). The growth rates generally do not change much at diameters larger than $10 \mathrm{~nm}$, so we provide the average growth rate between diameters of 10 and $20 \mathrm{~nm}$, the same range used to determine the observed growth rates.

\subsection{HYSPLIT back trajectories}

In order to assess the influence of air mass source upon each event, the NOAA HYSPLIT model (Draxler and Rolph, 2012; Rolph, 2012) with NAM meteorological data was used to obtain $48 \mathrm{~h}$ air mass back trajectories (Fig. 1d-f). The model was initialized at $\sim 250 \mathrm{~m}$ above ground level (a.g.l.) at the time of the observed NPF onset for each trajectory; a total of 24 trajectories were output for each event day using the HYSPLIT ensemble feature that perturbs the start height by small increments vertically and horizontally.

\section{Results}

\subsection{April: growth by primarily organics}

On 19 April 2013, an NPF event was recorded by the SMPS beginning around 12:00 central daylight time (CDT) (Fig. 1a); the three growth-rate methods (see Sect. 2.4.1) provided a possible growth-rate range of $1.6-8.8 \mathrm{~nm} \mathrm{~h}^{-1}$ (Table 3). The gas-phase concentrations of each measured species, averaged through this $10-20 \mathrm{~nm}$ diameter growth period, are presented in Table 1, and the time series of these observations in Fig. 2a-b. Note that oxalic acid was not measured by the cluster CIMS for this day. The ratio of measured oxalic-acid concentration to measured malonic-acid concentration was approximately 0.1 throughout the campaign when oxalic-acid data were available; thus, we assume that a baseline concentration of oxalic acid was present at 0.1 times the measured concentration of malonic acid for this day. Some notable features of the gas-phase data for 19 April (Fig. 2a-b) include relatively low sulfuric-acid concentrations $\left(\sim 2 \times 10^{6} \mathrm{~cm}^{-3}\right)$, which should only contribute to growth rates of about $0.08 \mathrm{~nm} \mathrm{~h}^{-1}$ (assuming kinetic regime growth, an accommodation coefficient of 1 , and a temperature of $283 \mathrm{~K}$ ), or approximately $10 \%$ of the observed rates. Conversely, the concentrations of ammonia and amines are sufficiently high (100-1000 pptv) that they could play a role in sulfuric-acid neutralization and organic-salt formation. The TDCIMS particle-phase ion-fraction data (Fig. 2c-d) show primarily organics with some amines present in the particle phase, indicating that growth by acid-base reactions of organic acids and amines and/or irreversible condensation of ELVOCs is possible. As mentioned previously, we currently have no unequivocal way to distinguish between organic acids and ELVOCs or higher-volatility nonreactive organics in the TDCIMS. The organics categories presented (organics, organics with $\mathrm{S}$, and organics with $\mathrm{N}$ ) should be taken as the sum total of organics (excluding amines) detected by the TDCIMS. The TDCIMS also shows a presence of nitrate (the nitrate (ox/inorg) category) later on in the growth event. We do not expect to see significant inorganic nitric acid in the growing of sub-50 nm particles, as ammonium nitrate tends to undergo equilibrium-limited growth in submicron particles and partition proportionally to the particle mass distribution (Zhang et al., 2012b). The possibility that much of the observed ox/inorg nitrate signal arises from decomposition or ion-molecule reactions of organic nitrates cannot be excluded. Furthermore, the TDCIMS shows heightened sensitivity to inorganic nitrate with respect to sulfate (Smith et al., 2004; Lawler et al., 2014). Due to all of 
these uncertainties, we hesitate to attribute significant growth from inorganic nitrate.

The 48 h HYSPLIT trajectory for 19 April (Fig. 1d) shows the flow coming from the northwest. The predicted trajectories appear to be subsiding from the free troposphere over the time period and thus likely only experience surface emissions during the last $18 \mathrm{~h}$ before passing through the Central Facility at Lamont, OK. The surface emissions would likely be coming from central/western Kansas, through primarily agricultural regions and no major urban areas, consistent with the low sulfuric-acid concentrations. Based on these back trajectories, we hypothesize that the air mass obtained biogenic SOA precursors from the region north of the SGP site as well as high levels of gas-phase bases due to emissions from agricultural practices.

The MABNAG simulations for this day are able to corroborate the predominance of organics in the particle phase. Our base simulation, MAL/10ox/DMA_Lam (Fig. 2e-g; Fig. 3) predicts a growth rate of $1.4 \mathrm{~nm} \mathrm{~h}^{-1}$ with $16 \%$ mole fraction from sulfuric acid, $\ll 1 \%$ from organic acid, $24 \%$ from ammonia, $9.1 \%$ from amines, and $50 \%$ from ELVOCs. Figure 3 shows the final dry particle compositions by mole fraction (left-hand bars) and mass fraction (right-hand bars) across our sensitivity cases. Details of MABNAG-predicted ion concentrations are given in Table S1 of the Supplement. On a molar basis across cases, MABNAG shows (Fig. 3) negligible $(<5 \%)$ amounts of organic acid in the particle phase, except for MAL_LoVP/100ox cases (an upper bound for organic-acid uptake due to lowered vapor pressure and increased gas-phase concentration), which show up to $18 \%$ of the particle was composed of organic acid. Malonic acid has a lower vapor pressure than oxalic acid, and thus more malonic acid is able to enter the particle phase than oxalic acid. The ELVOC mole fraction tends to be around $50 \%$ for most cases, corresponding to ELVOCs composing over $80 \%$ of the dry particle by mass fraction. There is a smaller (around $35 \%$ ) ELVOC mole fraction predicted for the high organic-acid cases. Since we do not know the actual contributions to growth from ELVOCs (or higher-volatility nonreactive organics) versus organic acids from the TDCIMS data, we cannot determine the accuracy of these individual species predictions. However, as the TDCIMS shows very small particle-phase contributions from bases even though high gas-phase base concentrations were also observed, this corroborates that the growth may be dominated by nonreactive organics. We see that MABNAG predicts that approximately $\sim 16 \%$ of the particle is composed of sulfuric acid by mole (with associated ammonia). No sulfuric acid appears directly in the TDCIMS ion spectra: thus, MABNAG appears to overpredict the contribution of sulfuric acid (and associated ammonia) for this day relative to the TDCIMS ion fractions. However, since sulfuric-acid vapor concentrations were non-zero, we expect some sulfuric acid in the particle phase. The most likely reason for the discrepancy is low signal-to-noise in the TDCIMS during this period, resulting from low collected particle mass. The TDCIMS data show some amine/amides in the particle phase: the most amine was predicted with DMA_Lam cases (9-11\% by mole) and this compares most closely to the TDCIMS ion fractions of the amine particle-phase predictions. All TMA_Lam cases predict less than $1 \%$ amines by moles in the particle phase and thus likely are not realistic inputs for this day. The majority of our simulations predict that less than $1 \%$ of the particle is organic acid by mole; thus, the contribution to particle growth from organic salt formation would be negligible, even when including the contribution from associated bases. Thus, we expect the majority of growth from organics to be coming from nonreactive organics (ELVOCs in our simulations) for this day.

The modeled growth rate is around $1.4 \mathrm{~nm} \mathrm{~h}^{-1}$ for most cases with a few cases (MAL_LoVP/100ox cases) reaching up to $1.7 \mathrm{~nm} \mathrm{~h}^{-1}$. When we compare the modeled growth rates to our three growth-rate methods that attempt to capture the observed growth rates, we see that the leading-edge method gave the highest growth-rate estimate at $8.8 \mathrm{~nm} \mathrm{~h}^{-1}$ and the $D_{\mathrm{p}}$-mode method gave the lowest estimate, at $1.6 \mathrm{~nm} \mathrm{~h}^{-1}$. However, a visual inspection of the best-fit lines of these two methods (Fig. S1) shows that the leading-edge method appears to overpredict the growth rate (the slope of the best-fit line is the growth rate in $\mathrm{nm} \mathrm{h}^{-1}$ ). The $D_{\mathrm{p}}$-mode method could be slightly underpredicted the growth rate but is not an unreasonable estimate. The visual method predicts a rate of $3.3 \mathrm{~nm} \mathrm{~h}^{-1}$. Therefore, we are more inclined to believe that the growth lies between these two latter estimates, e.g., $1.6-3.3 \mathrm{~nm} \mathrm{~h}^{-1}$. Thus, all MABNAG cases come close to or slightly underpredict the observed growth rates. We do note that the organics with $\mathrm{N}$ and $\mathrm{N}$ (ox/inorg) ion categories dominate the overall TDCIMS spectrum; as MABNAG currently does not account for nitrogen-containing species beyond ammonia and amines, this could account for some of the potential discrepancies in the particle growth rate and composition between model and observations. As organics are a very important part of this day's particle growth, our results are sensitive to our precursor and yield assumptions of ELVOCs, and for this day where ELVOCs dominated growth, a $50 \%$ uncertainty in ELVOC yield would correspond to close to a $50 \%$ uncertainty in growth rate (ELVOCs dominate the simulated volume fraction). Having more-direct measurements of VOCs and associated ELVOC yields will better constrain the ELVOC budget. However, even a $50 \%$ underprediction of the contribution from ELVOCs to growth would lead to a maximum growth rate of $2.1 \mathrm{~nm} \mathrm{~h}^{-1}$, which is on the low end of the growth-rate range that we have calculated from the measurements. Thus, our low bias in growth rate for this day may not be from the ELVOC concentration uncertainties alone. Our lack of LVOCs, SVOCs, and accretion reactions from SVOCs likely also contribute to our potential underprediction, as these species will contribute more with increasing particle size. 

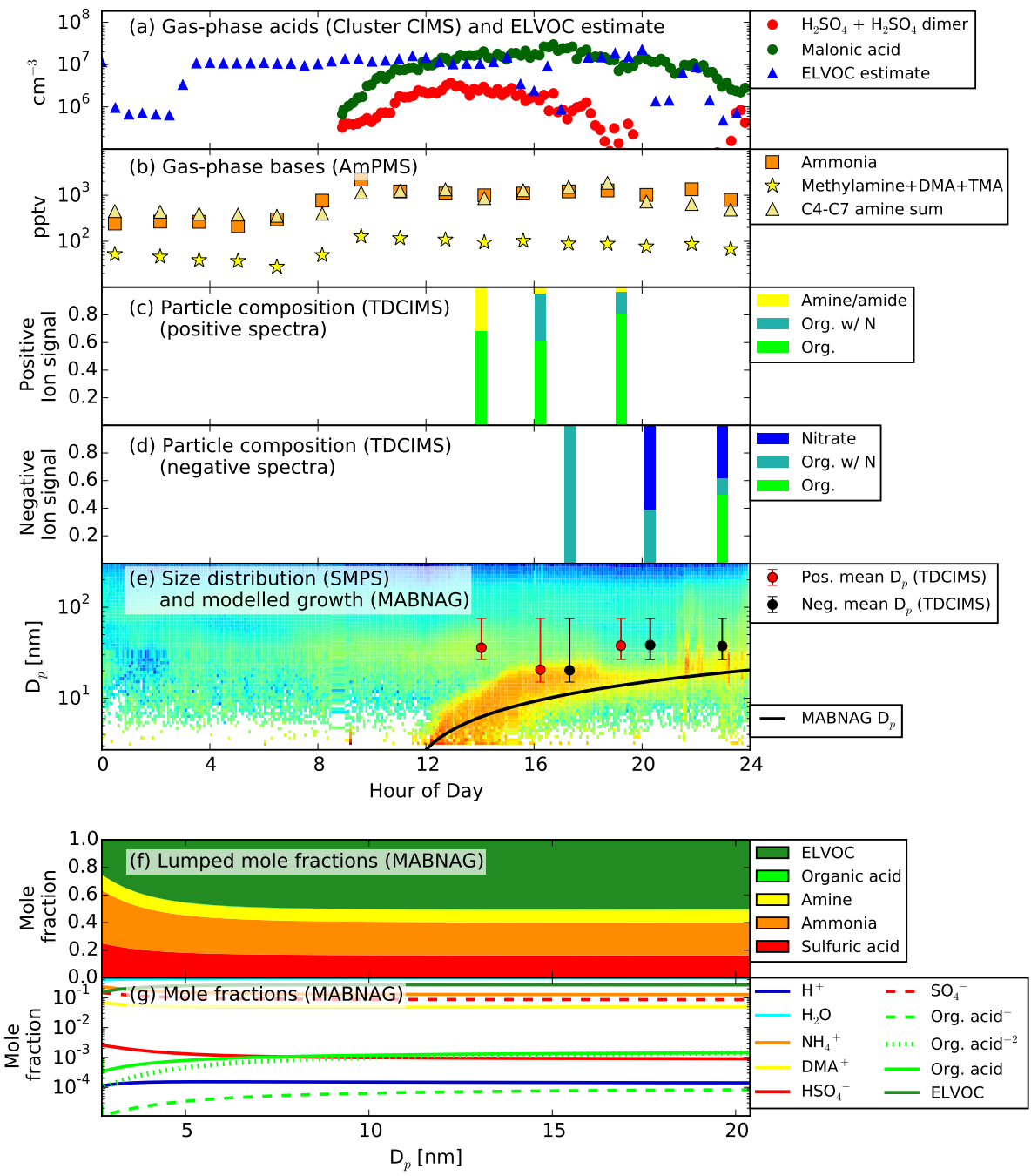

Figure 2. Measurements and MABNAG predictions for the base-case simulation, MAL/10ox/DMA_Lam, for 19 April 2013. (a) Gas-phase acids and ELVOC estimate. Oxalic acid was not measured for this day; the cluster CIMS was not operational before 09:00 CDT for this day. (b) Gas-phase bases. (c-d) Particle-phase data. The TDCIMS was not operational before 14:00 CDT. (e) Size distribution from the three merged SMPSs with the modeled growth rate (black line). Overlaid is the mean collection diameter from the TDCIMS for the positive (red points) and negative (black points) signals. (f-g) Modeled particle composition as a function of size: (f) shows the lumped mole fractions (excluding water) of each species, including any dissociation products; (g) shows the individual mole fractions of each species and its dissociation products. $\mathrm{NH}_{3}$ and DMA are not shown as both species dissociate almost entirely to $\mathrm{NH}_{4}^{+}$and $\mathrm{DMA}^{+}$, respectively. $\mathrm{OH}^{-}$is not shown as its concentration is extremely low $\left(\sim 10^{-15}\right)$.

Overall, the observations from 19 April clearly show that organic species contribute heavily to growth: the MABNAG results corroborate this, and the MABNAG simulations further show that ELVOCs dominate over organic acids for all sensitivity cases. As the TDCIMS shows small amounts of particle-phase ions from bases even though high gas-phase base concentrations were also observed, this corroborates that the growth may be dominated by nonreactive organics. Furthermore, as ELVOCs are larger molecules than the other species considered here, their contributions to growth rates are even larger than their contribution to mole or ion fractions. Finally, we hypothesize that LVOCs, and perhaps
SVOCs or accretion reactions, are contributing to growth within the $10-20 \mathrm{~nm}$ diameter range, as MABNAG possibly underestimates growth without these species/reactions.

\subsection{May: growth by primarily sulfuric acid and ammonia}

On 9 May 2013 (Fig. 4), two growth events were observed; we focus our analysis on the second event, which began around 13:00 CDT. The SMPSs and cluster CIMS both experienced instrument failure from 17:30 CDT onwards on this day; the cluster CIMS was also not operational before 

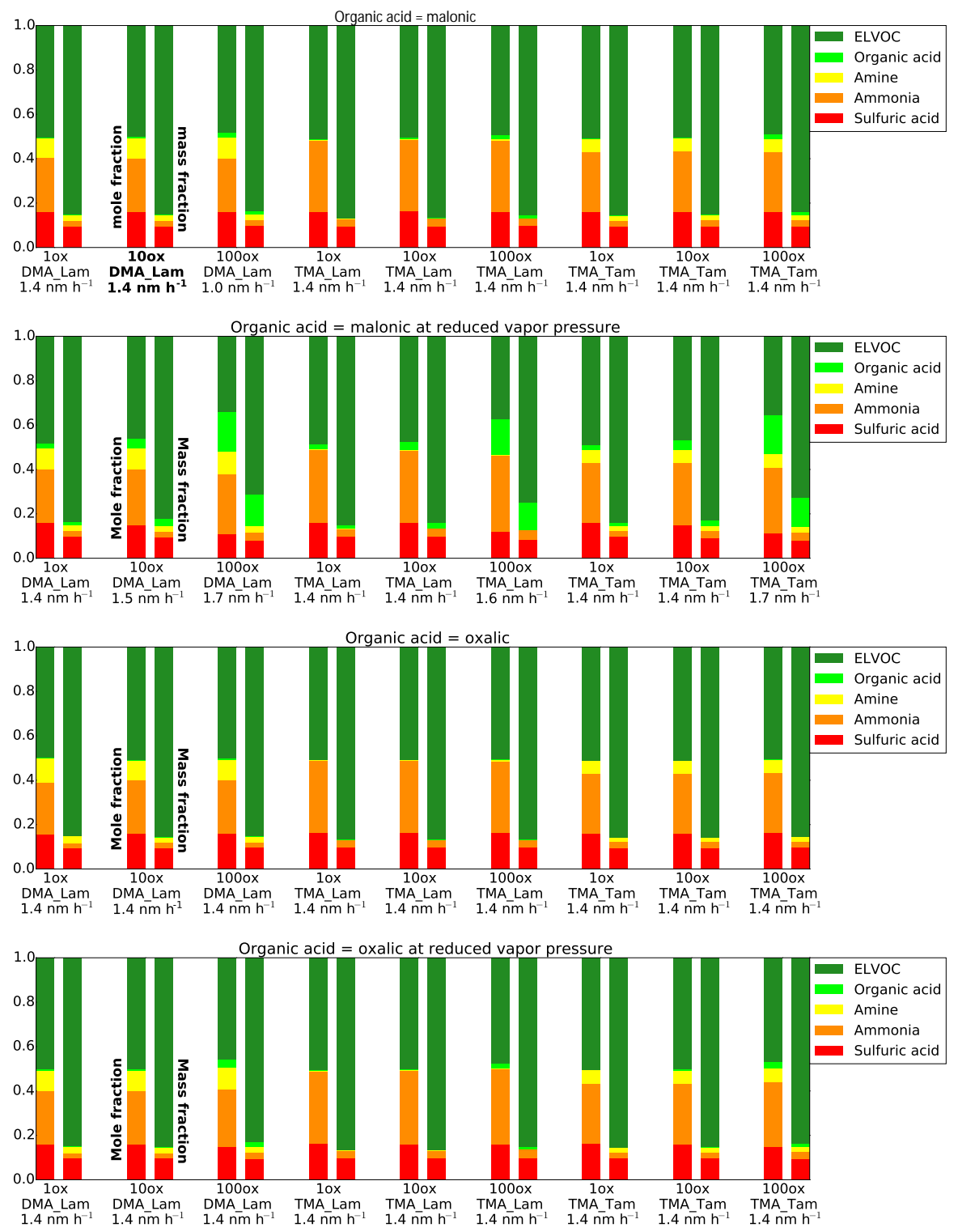

Figure 3. The final dry particle composition for each sensitivity case for 19 April 2013, as both lumped mole fraction (left-hand bars) and lumped mass fraction (right-hand bars). The top and third rows represent each case that uses the properties of malonic acid and oxalic acid, respectively, at the best-fit vapor pressure from Bilde et al. (2015) for the chemical properties of the organic-acid inputs. The second and forth rows represent each case that uses the properties of malonic acid and oxalic acid, respectively, at 1 order of magnitude less in vapor pressure than the best-fit value for the chemical properties organic-acid inputs. 1ox, 10ox, and 100ox refer to cases using the measured (1ox) concentration, 10 times (10ox) the measured concentration, and 100 times (100ox) the measured concentration of oxalic acid, respectively, each summed with the measured malonic-acid concentration, for the organic-acid concentration input. DMA and TMA refer to cases using the properties of dimethylamine and trimethylamine, respectively, for the chemical properties of the amine inputs. Lam and Tam refer to cases using the sum of the concentrations of only the light amines measured (methylamine, DMA, and TMA) and the sum of the concentrations of the total amines measured (including $\mathrm{C} 4-\mathrm{C} 7$ amines but excluding diamines), respectively, for the amine concentration input. The bottom row of each case label shows the growth rate for that case in $\mathrm{nm} \mathrm{h}^{-1}$. The bolded case label (first row, second case) represents our base case (see Fig. 2 and text). 

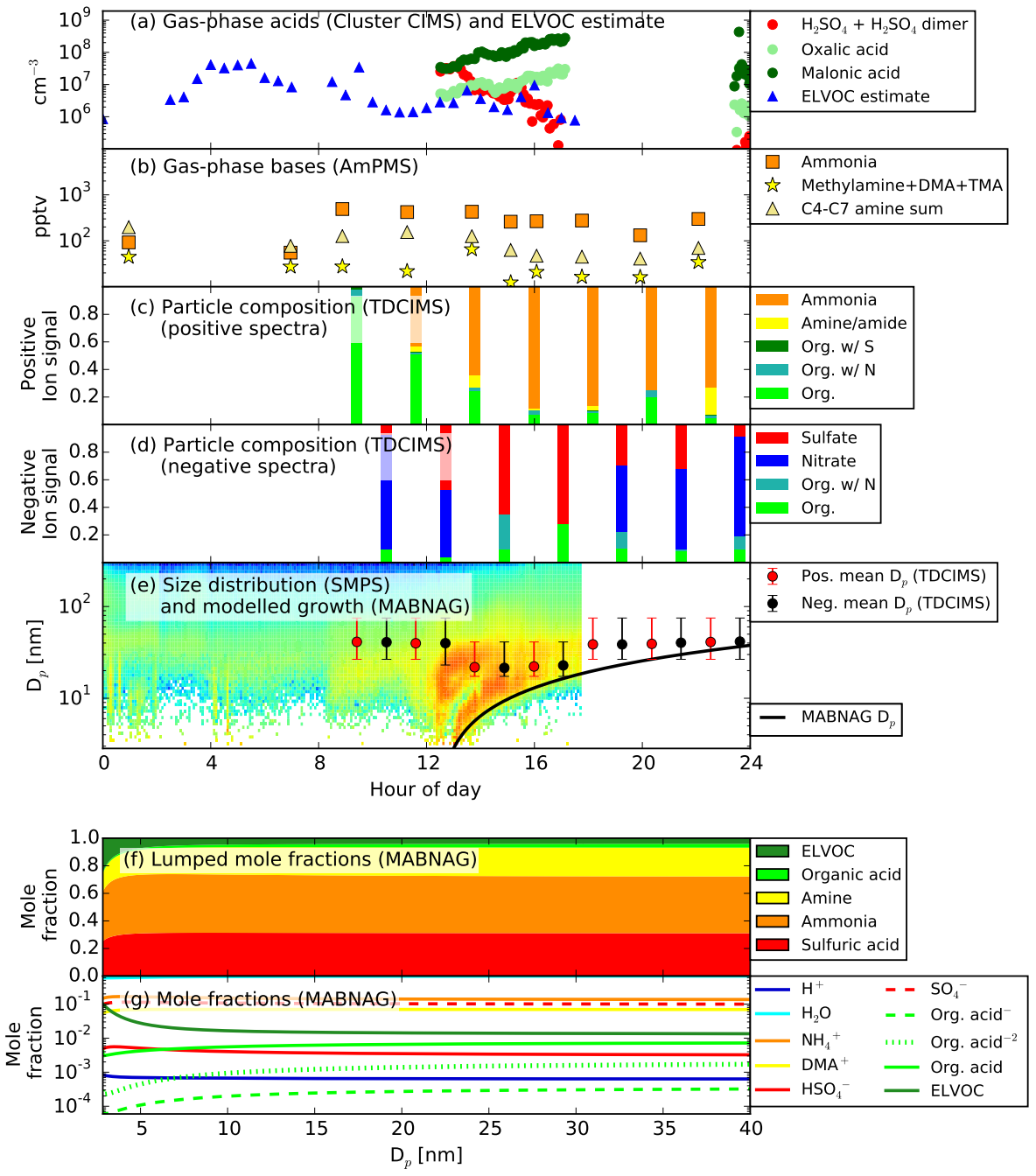

Figure 4. Measurements and MABNAG predictions for the base-case simulation, MAL/10ox/DMA_Lam, for 9 May 2013. (a) Gas-phase acids and ELVOC estimate. The cluster CIMS was not operational between 17:30 and 23:00 CDT for this day. (b) Gas-phase bases. The AmPMS was not operational between 02:00 and 06:00 CDT for this day. (c-d) Particle-phase data. The TDCIMS was not operational before 09:00 CDT for this day. (e) Size distribution from the three merged SMPSs with the modeled growth rate (black line). Overlaid is the mean collection diameter from the TDCIMS for the positive (red points) and negative (black points) signals. The SMPSs were not operational after 17:30 CDT for this day. (f-g) Modeled particle composition as a function of size: (f) shows the lumped mole fractions (excluding water) of each species, including any dissociation products; $(\mathbf{g})$ shows the individual mole fractions of each species and its dissociation products. $\mathrm{NH}_{3}$ and DMA are not shown as both species dissociate almost entirely to $\mathrm{NH}_{4}^{+}$and $\mathrm{DMA}^{+}$, respectively. $\mathrm{OH}^{-}$is not shown as its concentration is extremely low $\left(\sim 10^{-15}\right)$.

12:00 CDT. However, the two instruments captured enough of the event to inform our analysis and provide modeling inputs. By 17:30, the three growth-rate methods provide a possible growth-rate range of $2.4-11.3 \mathrm{~nm} \mathrm{~h}^{-1}$. The cluster CIMS measured high sulfuric acid for this day $(\sim 2 \times$ $10^{7} \mathrm{~cm}^{-3}$ ), sufficiently high for sulfuric acid to contribute significantly to condensational growth. The ammonia concentrations are somewhat higher than the amine concentrations. The TDCIMS shows a high amount of ammonia and sulfate, indicating the presence of ammonium sulfate contributing strongly to the growth of the particles. A small, but nontrivial, amount of organics and amines is seen in the particle phase as well.

The HYSPLIT back trajectory for 9 May (Fig. 1e) shows flow from the south, through much of central/east central Texas. The predicted trajectories are entirely in the BL, allowing for the possibility of the air mass experiencing surface emissions throughout the entire previous $48 \mathrm{~h}$. Many of the possible trajectories pass over or near the major metropolitan Dallas/Fort Worth region and extend into the industrial gulfcoast region; some of the trajectories extend towards the major metropolitan region of Houston. Both possible trajectory 

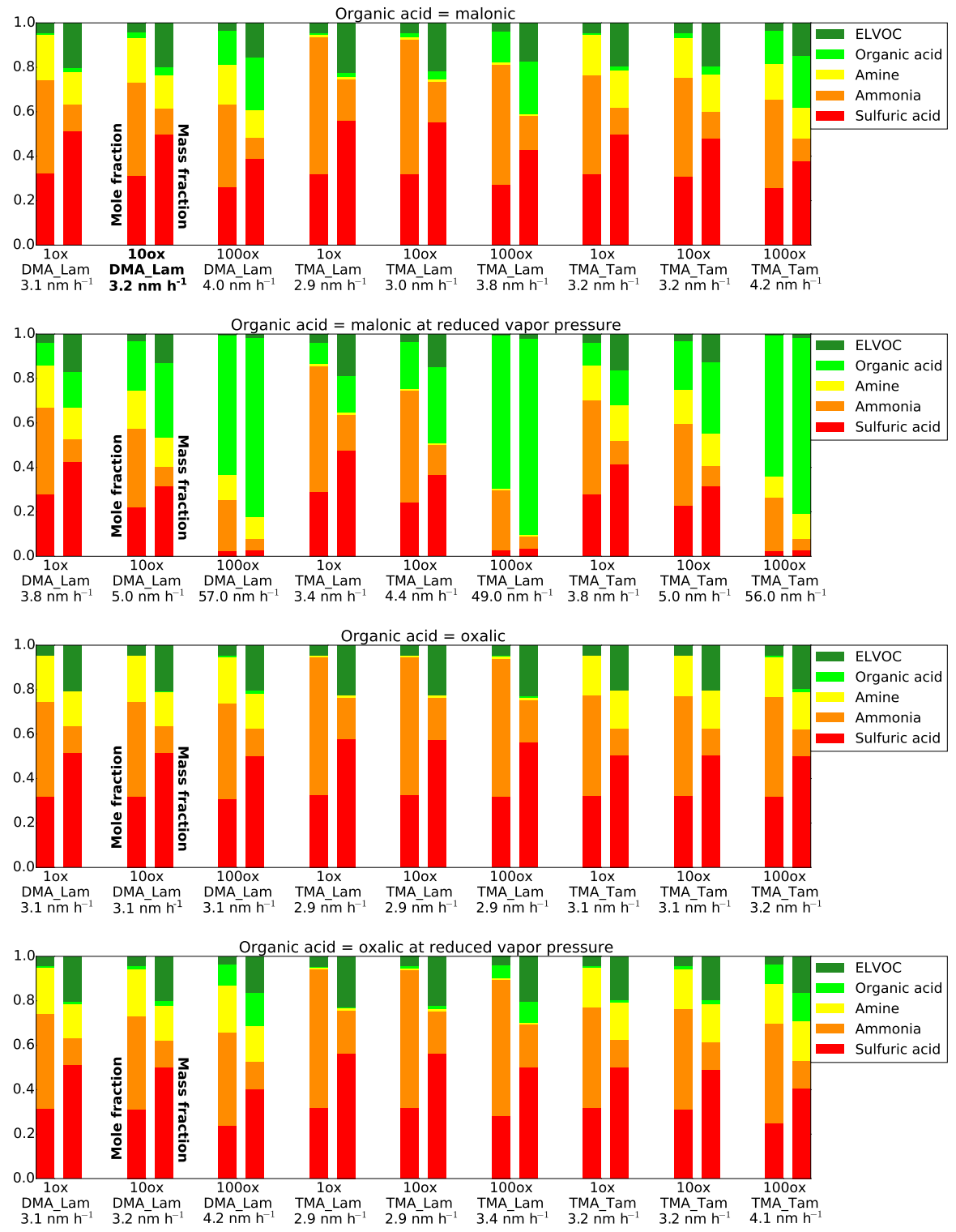

Figure 5. The final dry particle composition for each sensitivity case for 9 May 2013, as both lumped mole fraction (left-hand bars) and lumped mass fraction (right-hand bars). The top and third rows represent each case that uses the properties of malonic acid and oxalic acid, respectively, at the best-fit vapor pressure from Bilde et al. (2015) for the chemical properties of the organic-acid inputs. The second and forth rows represent each case that uses the properties of malonic acid and oxalic acid, respectively, at 1 order of magnitude less in vapor pressure than the best-fit value for the chemical properties organic-acid inputs. 1ox, 10ox, and 100ox refer to cases using the measured (1ox) concentration, 10 times (10ox) the measured concentration, and 100 times (100ox) the measured concentration of oxalic acid, respectively, each summed with the measured malonic-acid concentration, for the organic-acid concentration input. DMA and TMA refer to cases using the properties of dimethylamine and trimethylamine, respectively, for the chemical properties of the amine inputs. Lam and Tam refer to cases using the sum of the concentrations of only the light amines measured (methylamine, DMA, and TMA) and the sum of the concentrations of the total amines measured (including C4-C7 amines but excluding diamines), respectively, for the amine concentration input. The bottom row of each case label shows the growth rate for that case in $\mathrm{nm} \mathrm{h}^{-1}$. The bolded case label (first row, second case) represents our base case (see Fig. 4 and text). 
paths could contribute $\mathrm{SO}_{2}$ emissions to the air mass. Local agricultural practices could have contributed ammonia and amines to the air mass, explaining the high base concentrations present at the SGP site.

The MABNAG simulations for this day are able to capture ammonium-sulfate formation as the dominant growth pathway. Our base simulation, MAL/10ox/DMA_Lam (Fig. 4eg; Fig. 5), predicts a growth rate of $3.2 \mathrm{nmh}^{-1}$ with $31 \%$ of the particle composition by moles from sulfuric acid, $2.2 \%$ from organic acid, $42 \%$ from ammonia, $20 \%$ from amines, and $4.3 \%$ from ELVOCs. Most sensitivity cases (Fig. 5) predict approximately $60-90 \%$ of the particle is composed of sulfuric acid and ammonia by mole fraction. Only the MAL_LoVP/100ox (upper bound for organic-acid uptake) cases predict otherwise; these cases show over $60 \%$ of the particle to be organic acid by moles. However, these cases also show unrealistically high growth rates $(\sim 48$ $57 \mathrm{~nm} \mathrm{~h}^{-1}$ ). Based on these growth rates, we conclude that, at least for this day, growth cannot be realistically captured by the MAL_LoVP/100ox inputs; these cases will not be discussed further. The TDCIMS shows a small amount of organics and an even smaller amount of amine/amide in the particle composition. MABNAG predicts roughly $5-25 \%$ of the particle by moles to be organics (ELVOC plus organic acids) with less than $1 \%$ up to $5 \%$ of the organics by moles coming from ELVOCs. Thus, unlike 19 April, organic acid is predicted to dominate the organics contribution for this day. However, given that most cases predict a negligible amount ( $<3 \%$ by mole) of the particle to be composed of organic acid, the contribution to particle growth from organic-salt formation is still predicted to be minor for this day. On a molar basis, less than $1 \%$ up to $21 \%$ of the particle is predicted to be amines.

MABNAG predicts growth rates between 2.9 and $5 \mathrm{~nm} \mathrm{~h}^{-1}$, with the highest growth rates seen for LoVP cases. These LoVP cases tend to predict a moderate $(\sim 15-25 \%$ by mole fraction) amount of organics (organic acid + ELVOC) and ( $<1$ to $20 \%$ by mole fraction) amines in the particle phase, leading us to believe that the reduced vapor pressure of organic acids allows for the best-fit simulations compared to the measurements of particle growth and composition. When we consider our three growth-rate methods that attempt to capture the observed growth rates (Fig. S2), we again see that the leading-edge method predicts the highest growth rates, at $11.3 \mathrm{~nm} \mathrm{~h}^{-1}$, and the $D_{\mathrm{p}}$-mode method predicts the lowest, at $2.4 \mathrm{~nm} \mathrm{~h}^{-1}$. However, again, the best-fit line shows that the leading-edge method appears to be again overpredicting the actual growth rate - some of the larger diameters appear to be influenced by the mixing down of the first nucleation event. The $D_{\mathrm{p}}$-mode method could be slightly underpredicting the growth rates but the best-fit line does not seem unreasonable enough for us to preclude this growth rate. The visual method provides a growth rate of $5 \mathrm{~nm} \mathrm{~h}^{-1}$, but we acknowledge that there is still some uncertainty in this estimate. If we consider the range provided by the $D_{\mathrm{p}}$-mode and visual methods, 2.4 to $5.0 \mathrm{~nm} \mathrm{~h}^{-1}$, our MABNAG cases either match or slightly underpredict the observed growth rates. Any possible underprediction could again be from the uncertainty from the nitrogen-containing species that appear in the TDCIMS but are not accounted for in MABNAG, as well as our uncertainty in ELVOC concentrations and lack of LVOCs, SVOCs, and accretion reactions.

Overall, the observations from 9 May show a strong contribution from ammonia and sulfate (presumably ammonium sulfate), and the MABNAG simulations corroborate this growth pathway, with the highest average mole fractions of sulfuric acid and ammonia predicted in the particle phase of the 3 days. This growth pathway should be well represented in regional/global models provided that emissions are well resolved.

\subsection{May: growth by sulfuric-acid/bases/organics}

11 May 2013 (Fig. 6), similar to 9 May, shows two growth events; we focus our analysis on the second event, which began around 15:00 CDT. All instruments were fully operational during the growth event, which is observed to extend into 12 May. The particles grow to about $25-35 \mathrm{~nm}$ in diameter, and our three growth-rate estimates provide a possible growth-rate range of $5.6-8.3 \mathrm{~nm} \mathrm{~h}^{-1}$ in the 10 $20 \mathrm{~nm}$ diameter range. The sulfuric-acid concentration on this day $\left(\sim 4 \times 10^{6} \mathrm{~cm}^{-3}\right)$ is in between those from the other 2 growth days. As with the other days, there are high ammonia and amines concentrations (100-10000 pptv) throughout the event. The TDCIMS shows a mixed view of what is present in the particle phase during the growth event. There is a fairly constant and significant relative amount of sulfate present in the particle. However, at the beginning of the event, amines are the dominant base present, but by 21:00 the relative amine signal has decreased and at 23:00 ammonia is dominant. Both the positive and negative signals show significant contributions from organics. The TDCIMS negative ion data also indicate the presence of nitrate; as stated previously, we hesitate to attribute significant growth from nitrate due to the unknown sensitivity of the TDCIMS to nitrate. Overall, from the TDCIMS, it appears that both sulfate and organics, as well as bases, are important for growth, but we cannot assess the relative importance of ammonia to amines for growth from the observations.

The HYSPLIT back trajectory for 11 May originates primarily from the north, traveling through central Kansas and Nebraska before reaching SGP. Some of the predicted trajectories stay in the BL for the full $48 \mathrm{~h}$; others show subsidence from the free troposphere, making it difficult to assess how much of the air mass was influenced from surface emissions over the previous $48 \mathrm{~h}$. Regardless, the air mass passed through primarily agricultural regions and no major urban areas, similar to 19 April, but we are unsure of the source of the sulfate on 11 May. 

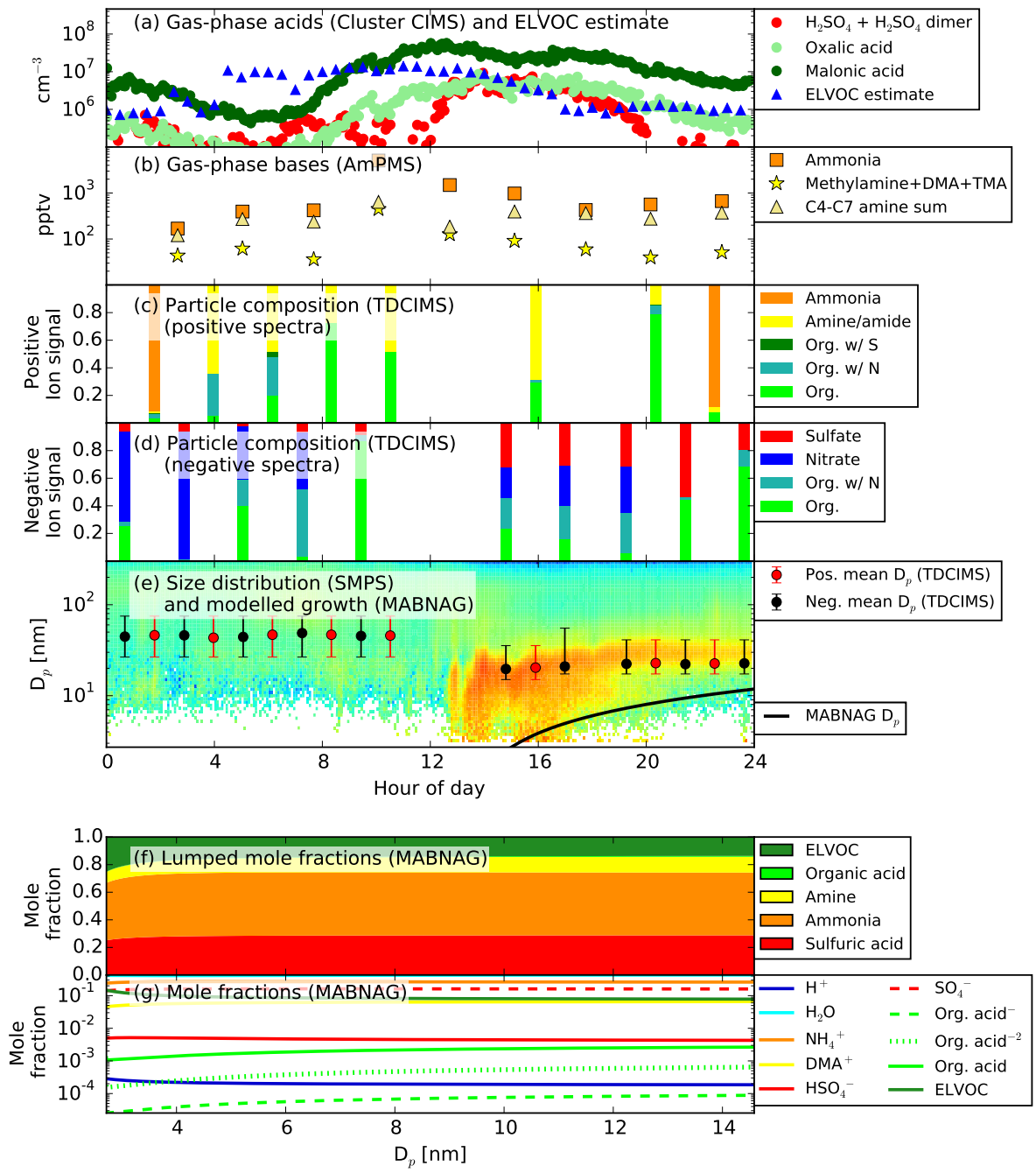

Figure 6. Measurements and MABNAG predictions for the base-case simulation, MAL/10ox/DMA_Lam, for 11 May 2013. (a) Gas-phase acids and ELVOC estimate. (b) Gas-phase bases. (c-d) Particle-phase data. (e) Size distribution from the three merged SMPSs with the modeled growth rate (black line). Overlaid is the mean collection diameter from the TDCIMS for the positive (red points) and negative (black points) signals. (f-g) Modeled particle composition as a function of size: (f) shows the lumped mole fractions (excluding water) of each species, including any dissociation products; (g) shows the individual mole fractions of each species and its dissociation products. $\mathrm{NH}_{3}$ and DMA are not shown as both species dissociate almost entirely to $\mathrm{NH}_{4}^{+}$and $\mathrm{DMA}^{+}$, respectively. $\mathrm{OH}^{-}$is not shown as its concentration is extremely low $\left(\sim 10^{-15}\right)$.

Similar to the TDCIMS data, the MABNAG simulations for this day show varying mixtures of sulfuric acid, organics, and bases. Our base simulation, MAL/10ox/DMA_Lam (Fig. 6e-g; Fig. 7), predicts a growth rate of $0.9 \mathrm{~nm} \mathrm{~h}^{-1}$ with $29 \%$ of the particle composition by mole from sulfuric acid, $\ll 1 \%$ from organic acid, $46 \%$ from ammonia; $11 \%$ from amines, and $14 \%$ from ELVOCs. Across cases (Fig. 7), we see that roughly $10-30 \%$ by mole fraction of the particle is predicted to be sulfuric acid, in reasonable agreement with the TDCIMS data. MAL_LoVP/100ox (upper bound for organic-acid uptake) cases predict up to $46 \%$ of the particle moles to be organic acid; the rest of the cases predict less than $1 \%$ up to $5 \%$ of the particle moles to be organic acid. Conversely, MABNAG predicts roughly $5-25 \%$ of the moles in the particle to be from ELVOCs, with the lowest relative ELVOC contribution seen in MAL_LoVP/100ox cases. Since the TDCIMS shows a variable amount of organics throughout the event, and we do not know the actual individual contributions from ELVOCs and organic acids nor are we accounting for any higher-volatility neutral organic species (e.g., LVOCs and SVOCs), we cannot conclude which set of organics inputs best captures this day and do not exclude any set of inputs for being unrealistic. MABNAG predicts mole fractions of $35-55 \%$ for ammonia and less than $1 \%$ up to $11 \%$ for amines (with less than $1 \%$ amines predicted for all TMA cases). As the TDCIMS shows a large amount 

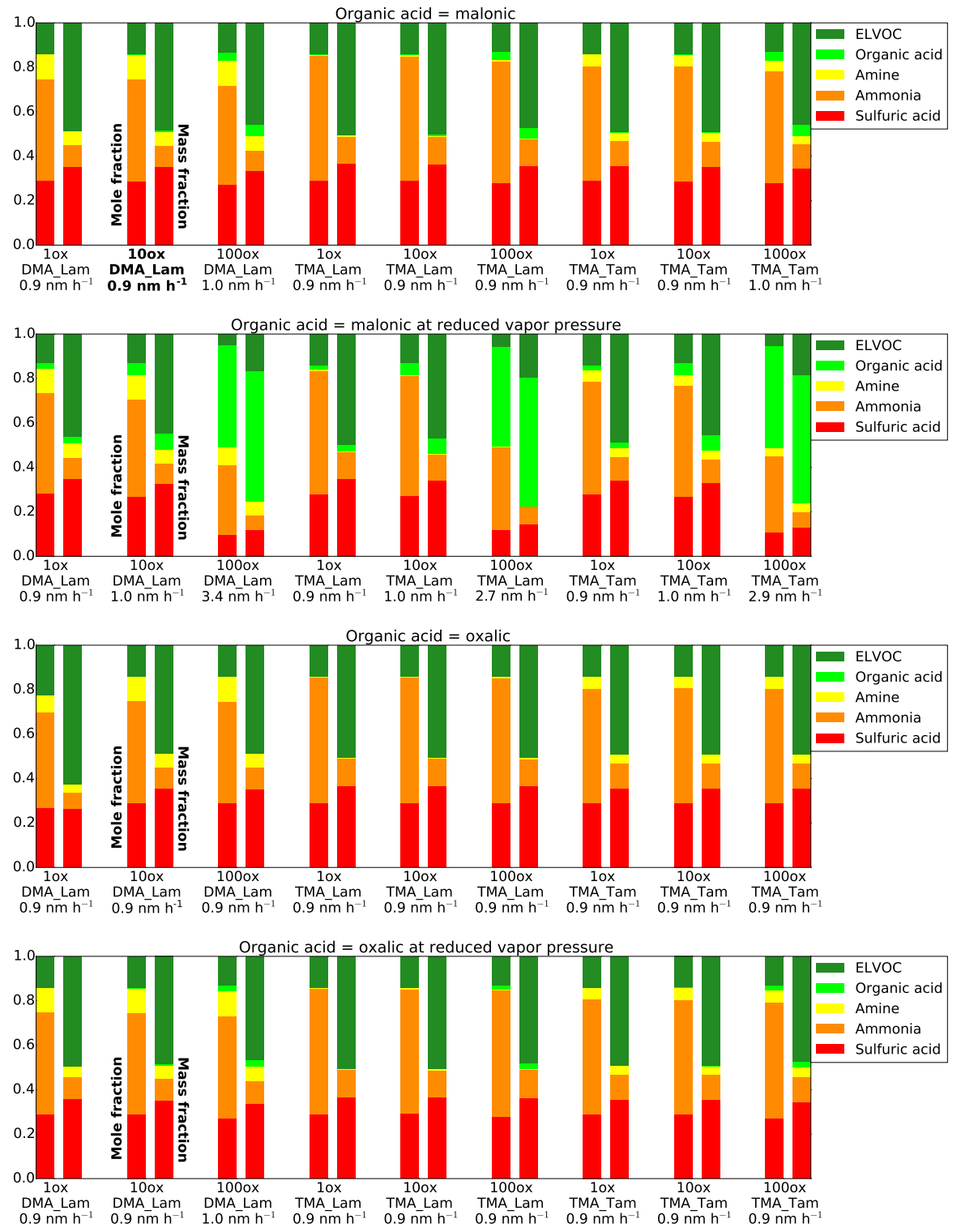

Figure 7. The final dry particle composition for each sensitivity case for 11 May 2013, as both lumped mole fraction (left-hand bars) and lumped mass fraction (right-hand bars). The top and third rows represent each case that uses the properties of malonic acid and oxalic acid, respectively, at the best-fit vapor pressure from Bilde et al. (2015) for the chemical properties of the organic-acid inputs. The second and forth rows represent each case that uses the properties of malonic acid and oxalic acid, respectively, at 1 order of magnitude less in vapor pressure than the best-fit value for the chemical properties organic-acid inputs. 1ox, 10ox, and 100ox refer to cases using the measured (1ox) concentration, 10 times (10ox) the measured concentration, and 100 times (100ox) the measured concentration of oxalic acid, respectively, each summed with the measured malonic-acid concentration, for the organic-acid concentration input. DMA and TMA refer to cases using the properties of dimethylamine and trimethylamine, respectively, for the chemical properties of the amine inputs. Lam and Tam refer to cases using the sum of the concentrations of only the light amines measured (methylamine, DMA, and TMA) and the sum of the concentrations of the total amines measured (including $\mathrm{C} 4-\mathrm{C} 7$ amines but excluding diamines), respectively, for the amine concentration input. The bottom row of each case label shows the growth rate for that case in $\mathrm{nm} \mathrm{h}^{-1}$. The bolded case label (first row, second case) represents our base case (see Fig. 6 and text). 
of amine/amides at the beginning of the event and a large amount of ammonia at the end of the event, we cannot determine which set of base inputs best capture this day either. The majority of our simulations predict $<5 \%$ by mole of the particle to be organic acid, thus again leading to only minor contributions from organic-salt formation to particle growth.

Similar to 19 April and 9 May, MABNAG tends to underpredict the growth rate for this day, with most cases predicting growth at around $0.9-1 \mathrm{~nm} \mathrm{~h}^{-1}$. Our three growth-rate methods are in moderately close agreement with each other for this day, with a possible range of 5.6 to $7.5 \mathrm{~nm} \mathrm{~h}^{-1}$. It is difficult to distinguish between the first and second growth events for this day, and our observed growth rates could be biased high due to mixing from the first growth rate. However, the majority of MABNAG cases predict a growth rate of $0.9-1 \mathrm{~nm} \mathrm{~h}^{-1}$; even if our observed growth rates are biased high, it is still likely that MABNAG underpredicts growth rates for this day. We do note that the MAL_LowVP/100ox cases show slightly higher growth rates at $2.7-3.4 \mathrm{~nm} \mathrm{~h}^{-1}$, which come closer to the possible observed growth rates. We do note that as MABNAG appears to be underpredicting the growth rates more than for 19 April or 9 May that the MABNAG-predicted particle compositions (Figs. 6 and 7) are possibly less representative of the actual particle compositions. However, we reiterate our hypothesis that the underpredictions could be from the nitrogen-containing species that are detected in the TDCIMS but are not accounted for in MABNAG, as well as our uncertainty in ELVOC concentrations and lack of LVOCs, SVOCs, and accretion reactions. Furthermore, this day shows a more variable particle-phase spectrum than 19 April or 9 May, as well as a more poorly defined second growth event (Fig. 1c), making the observed growth rates difficult to determine. The TDCIMS particle composition information is only qualitative. Thus, we will not speculate what differences are possible between observed and modeled particle composition.

Overall, the observations from 11 May show that organics, sulfate, and bases (either amines or ammonia) are all important for the evolution of this new-particle growth event. The MABNAG simulations corroborate this, with the organic contribution being from ELVOCs. Growth by LVOCs, SVOCs, and/or organic accretion may also be important, as MABNAG simulations generally underestimated growth and the mole fraction of organics on this day, relative to observations. The back trajectories on this day are similar to those from 19 April, though we are unsure of the reason for the difference in sulfuric-acid concentrations between the 2 days. Similar to 19 April, the TDCIMS tends to show more organics than bases that would remain after neutralizing the observed particle-phase sulfuric acid, corroborating that the organics in the particle phase are likely dominated by nonreactive organics.

\subsection{Synthesis across days}

For the 3 days analyzed here, new-particle growth at SGP can be driven by combinations of sulfuric acid (with associated bases) and nonreactive organics, of which ELVOCs contribute a substantial fraction (at least for the yields assumed here). The exact mixture of these pathways depends on the air mass history. We found that the contribution of small organics and organic salts, such as oxalic and malonic acid and associated salts formed with ammonia and amines, to growth may be minor at SGP. However, decreasing the assumed vapor pressure and/or increasing the vapor-phase concentration of the organic acids (within uncertainty ranges) increased the contribution of the small organic acids on some days. Both modeling and measurements show that both ammonia and amines can act as the bases in growing nanoparticles at SGP. While the MABNAG simulations here are limited in the number of species and growth processes considered, the model is capable of qualitatively differentiating the dominant particle-phase compositions between the 3 days: organics on 19 April, inorganics on 9 May, and a mixture on 11 May. We do not see that one set of assumptions in MABNAG best captures all 3 days (Figs. 3, 5, and 7) and instead present these results as a basis for further research, especially into the contribution of higher-volatility organic species to growth.

Although not discussed above, we also considered the effects of RH uncertainty on our results: 19 April and 11 May both have much lower relative humidities (32 and $36 \%$, respectively) than 9 May (69\%). MABNAG shows a moderate sensitivity to RH. We ran a simulation of all days and all cases at $80 \%$ RH (not shown); the simulations showed an increase in the dissociation of both malonic and oxalic acids as well as an increase in growth rate for all cases (in part due to increased water uptake), with most cases showing an associated increase in the mole fraction of organic acid. The increase in growth rate depended on the organic-acid concentration input and vapor pressure, with the highest increases seen for LoVP/100ox cases. These higher-RH results may be applicable since the BL was well-mixed on the three nucleation days, and the RH increases with height within wellmixed BLs. Thus, using surface-based measurements for RH may be a lower bound for RH and cause growth underestimates.

\subsection{Limitations of this study}

While we have shown that MABNAG can quantitatively capture the dominant species that contribute to growth for observed growth events, this study is limited in its scope due to the following uncertainties and limitations.

- There are significant uncertainties in both the measured organic-acid concentrations and chemical properties. The measured oxalic-acid concentrations could be up to 100 times too low due to the uncertainty in the oxalic-acid detection efficiency in the cluster CIMS. 
Also, the malonic-acid sensitivity is not known. The saturation vapor pressures of malonic and oxalic acid show variation amongst the reported values, and our simulation results are sensitive to their vapor pressures within the reported ranges.

- There is not yet a constrained ELVOC budget from the oxidation of atmospheric VOCs. The yields from different species and under different atmospheric conditions are just beginning to be quantified. The fixed $3 \%$ yield that we used here is preliminary and must be refined as the community continues to learn more about ELVOCs. The confidence in our estimated ELVOC budget also is limited by uncertainties stemming from using MEGAN output for the monoterpene-concentration estimate and by uncertainties in the local ozone concentrations.

- Large (greater than C3) amines are relatively unstudied in the field as of yet, and the exact identification of these molecules is difficult with current instrumentation. As a result, estimating the thermodynamic properties such as $\mathrm{pKa}$ and vapor pressure that determine abilities of these amines to participate in acid-base reactions is difficult, and we can only provide estimates of these contributions.

- Our particle-phase composition measurements from the TDCIMS provide only qualitative information for the organic species present in the growing particles. We do not know the exact molar contributions to the particles from each species, as the TDCIMS is not calibrated for each of the many organic compounds that are detected due to fragmentation during desorption as well as chemical ionization of desorbed gas-phase ions. Perhaps more significantly, particle-phase "matrix effects" may impact the efficiency by which organic compounds are desorbed and ionized; such matrix effects are difficult to assess since they depend on the coexisting compounds in the particles and the phase of the particles.

- We did not know the parent molecule(s) of the nitrate signal in the TDCIMS ions that is classified as either inorganic or oxidized nitrate. This signal appears nontrivially during part of every growth event analyzed, but we are without knowledge of its origin.

- The MABNAG model, as used here, only simulates one organic acid and one amine in any individual simulation. This limits our ability to determine the contribution of combinations of organic acids and amines to growth through acid-base reactions and condensation (for the less-volatile organic acids). Instead, we present only limiting cases that inform us of the potential contributions of organic acids and amines if the sum of oxalic and malonic acid had the properties of one these species.
- We did not account for the contribution of LVOCs or SVOCs to condensational growth as there were no gas concentration measurements of such compounds. As particles grow beyond initial cluster sizes, the LVOCs will begin to contribute to growth and likely are a significant contributor for particles as they approach diameters of $10 \mathrm{~nm}$ (Pierce et al., 2011). As the particle continues to grow, the SVOCs may also be a nontrivial contributor to growth (Pierce et al., 2011). Thus, the growth by nonreactive organics is likely underestimated in this study.

- We did not account for accretion reactions that could contribute to particle growth as there were no observations to constrain the contribution of accretion products to new-particle growth during this study. Accretion has been observed in the laboratory in particles greater than $4 \mathrm{~nm}$ in size (Wang et al., 2010) and thus has the potential to contribute to growth even at these smaller particle sizes.

- We assumed in MABNAG that all species in the particle phase instantaneously homogeneously mix into a liquid phase: this assumption ignores any particle-phase diffusion limitations that can arise from heterogeneous particle phases. It is estimated that such diffusion limitations can begin to matter at particle sizes greater than $20 \mathrm{~nm}$ in diameter.

- We use RH measured at the surface, which may be an underestimate of RH in other portions of a well-mixed BL. MABNAG sensitivity simulations with increased RH showed increased growth rates and contributions from organic acids.

\section{The Southern Great Plains: comparison to other campaigns}

The NPFS provided unique insights into new-particle formation events for the region during the spring of 2013, as both gas-phase and particle-phase measurements were taken concurrently in order to assess the species contribution to growth. We see that from 3 days of the campaign where all instruments were running, three different dominant growth mechanisms are present, from growth by primarily organics to growth by primarily ammonium sulfate to a mixture of growth from organics, sulfuric acid, and bases.

Previous field campaigns have taken place to similarly assess the growth of new-particle formation events in the continental BL. A review paper by Kulmala et al. (2004) and references therein considered over 100 field campaigns, both long-term and intensive, primarily at continental BL sites. Growth rates were found to be mainly within the 1$20 \mathrm{~nm} \mathrm{~h}^{-1}$ range in the mid-latitudes, and our events are within this range. Furthermore, for campaigns in which 
growth rates and gas-phase sulfuric acid were measured, it was found that sulfuric acid tended to account for only 10$30 \%$ of the observed growth rates (Kulmala et al., 2004); although water and ammonia accounted for some of the remaining growth, organic compounds are thought to comprise the remaining growth. Studies within the past few years have reported growth from either primarily organics (e.g., Smith et al., 2008; Kuang et al., 2010; Riipinen et al., 2011; Pierce et al., 2012) or inorganic components, primarily sulfate or ammonium sulfate (e.g., Bzdek et al., 2012).

Online particle-composition measurements of sub-micron aerosols are a relatively new and still-evolving measurement technique. Smith et al. (2004) reported the first such measurements, using the TDCIMS to examine 6-20 nm particles. Another recently developed instrument is the nano aerosol mass spectrometer (NAMS) (Wang et al., 2006; Wang and Johnston, 2006; Pennington and Johnson, 2012), which reports quantitative elemental composition of nanoparticles in the $10-30 \mathrm{~nm}$ range. Of the recent studies that have used combined gas-phase measurements with particle-phase measurements (using either the TDCIMS, NAMS, or both) to determine dominant growth mechanisms (e.g., Smith et al., 2008; Bzdek et al., 2012, 2014), this study is, to our knowledge, unique in reporting distinctly different dominant growth pathways for separate yet temporally closely spaced new-particle growth events. However, it is highly unlikely that SGP is truly unique in this regard; instead the findings of this paper point towards the value of investigating more field sites influenced by mixtures of anthropogenic and biogenic emission using similar combinations of gas-phase and particle-phase measurements.

\section{Conclusions}

In this study, we sought to understand the species/mechanisms that contribute to the growth of newly formed particles at the US Department of Energy Atmospheric Radiation Measurement program SGP field site in Oklahoma, US, and to find closure in particle growth rates and composition between the SGP measurements and the growth model, MABNAG. We analyzed data collected from 13 April to 25 May 2013 for the SGP NPFS. We focused the analysis on three new-particle formation and growth events occurring on 19 April, 9 May, and 11 May. These days had different dominant species contributing to growth: 19 April was primarily from organics, 9 May was from ammonium sulfate, and 11 May was from organics, amines/ammonia, and sulfate. MABNAG was constrained by the measured gas-phase concentrations of key atmospheric species present during the growth event for each day, and we found that MABNAG qualitatively simulated the observed dominant species for each day under certain sets of assumptions. We saw that during the NPFS campaign, new-particle growth events can be explained by either sulfuric acid forming salts with atmospheric bases (either ammonia or amines), the condensation of primarily nonreactive organics, or a combination of these two. MABNAG can qualitatively capture different dominant growth pathways. It appears from the TDCIMS that most of the organics measured are likely nonreactive: when we assume equivalent detection efficiencies, there are generally more organics than there are bases. The MABNAG simulations support that the organics in the growing particles are likely nonreactive, with the nonreactive-organic ELVOC input species dominating the organic contribution to the particle growth over the organic-acid input species in almost every sensitivity case.

MABNAG tends to underpredict the observed growth rates. Due to the strong organics signals in the TDCIMS, we propose that these low growth rates are mainly due to an underrepresentation of organic uptake in MABNAG, either by nonreactive condensation of LVOCs or SVOCs or particlephase accretion. Furthermore, the discovery of ELVOCs is relatively new and the ELVOC budget remains largely unconstrained.

Although we have not achieved complete closure in particle growth rates and composition between the SGP measurements and MABNAG simulations, we present this work as an important step towards understanding new-particle formation and growth events. We find that the relatively poorly understood ELVOC species can play a key role in the growth of particles through nonreactive condensation. However, organics of higher but still sufficiently low vapor pressures $\left(\sim<10^{0} \mathrm{\mu g} \mathrm{m}^{-3}\right.$ saturation mass concentration) are likely also important for growth and increase in importance with increasing particle size. Based on these findings, we encourage more field-based measurements that focus on the speciation and properties of organics, both in the gas phase and in particles. In particular, gas-phase ELVOC, LVOC, and SVOC measurements, found either through speciation or volatility measurements, would greatly inform future modeling efforts. These measurements are exceedingly challenging but as experimental techniques evolve, they will be invaluable in understanding and modeling both aerosol fundamentals and aerosol impacts on climate and human health.

\section{Data availability}

The data from the New Particle Formation Study campaign that were used in the analysis of this paper are available on the ARM DOE website by request (http://www.arm.gov/ campaigns/sgp2013npfs). E-AIM is freely available online at http://www.aim.env.uea.ac.uk/aim/aim.php. 


\section{Appendix A: List of abbreviations}

\begin{tabular}{|c|c|}
\hline $\begin{array}{l}\text { a.g.l. } \\
\text { AmPMS }\end{array}$ & $\begin{array}{l}\text { amove ground level } \\
\text { ambient pressure proton transfer } \\
\text { mass spectrometer }\end{array}$ \\
\hline ARM & $\begin{array}{l}\text { Atmospheric Radiation Measure- } \\
\text { ment }\end{array}$ \\
\hline BL & oundary layer \\
\hline VOC & $\begin{array}{l}\text { biological volatile organic com- } \\
\text { pound }\end{array}$ \\
\hline $\mathrm{CCN}$ & cloud condensation nuclei \\
\hline DT & ylight time \\
\hline CIMS & $\begin{array}{l}\text { chemical ionization mass spectrom- } \\
\text { eter }\end{array}$ \\
\hline PC & condensation particle counter \\
\hline $\mathrm{CS}$ & 1 \\
\hline DMA & mine \\
\hline DOE & ent of Energy \\
\hline$D_{\mathrm{p}}$ & particle diameter \\
\hline E-AIM & $\begin{array}{l}\text { Extended Aerosol } \\
\text { Model }\end{array}$ \\
\hline ELVOC & $\begin{array}{l}\text { Model } \\
\text { extremely low-volatility organic } \\
\text { compound }\end{array}$ \\
\hline $\begin{array}{l}\text { EPA } \\
\text { GR }\end{array}$ & $\begin{array}{l}\text { Environmental Protection Agency } \\
\text { growth rate }\end{array}$ \\
\hline HYSPLIT & $\begin{array}{l}\text { HYbrid Single-Particle Lagrangian } \\
\text { Integrated Trajectory }\end{array}$ \\
\hline IUPAC & $\begin{array}{l}\text { International Union of Pure and Ap- } \\
\text { plied Chemistry }\end{array}$ \\
\hline Lam & $\begin{array}{l}\text { sum of light }(\mathrm{C} 1-\mathrm{C} 3) \text { amines mea- } \\
\text { sured at SGP }\end{array}$ \\
\hline Lo-VP & $\begin{array}{l}\text { reducing the vapor pressure of the } \\
\text { organic-acid input in MABNAG by } \\
10^{-1}\end{array}$ \\
\hline
\end{tabular}

LVOC low-volatile organic compound

MABNAG Model for Acid-Base chemistry in NAnoparticle Growth

MAL malonic acid

MEGAN Model of Emissions of Gases and Aerosols in Nature

NAM North American Mesoscale model

NAMS nano aerosol mass spectrometer

NOAA National Oceanic and Atmospheric Administration

NPF new-particle formation

NPFS New Particle Formation Study

OX oxalic acid

PTR-MS proton transfer reaction-mass spectrometer

RH relative humidity

SGP Southern Great Plains

SMPS scanning mobility particle sizer

SOA secondary organic aerosol

SVOC semi-volatile organic compound

Tam sum of total amines measured at SGP

TDCIMS thermal decomposition chemical ionization mass spectrometer

TMA trimethylamine

UNIFAC UNIquac Functional-group Activity Coefficient method

VOC volatile organic compounds 


\section{The Supplement related to this article is available online at doi:10.5194/acp-16-9321-2016-supplement.}

Acknowledgements. This research was supported by the US Department of Energy's Atmospheric System Research, an Office of Science, Office of Biological and Environmental Research program, under grant nos. DE-SC0011780 and DE-SC0014469. We acknowledge the cooperation of the US Department of Energy as part of the Atmospheric Radiation Measurement (ARM) Climate Research Facility in hosting the NPFS at the Central Facility. In addition to data from the NPFS, we acknowledge the access of atmospheric condition data (temperature and relative humidity) from routine measurements at the Central Facility. Coty Jen was supported under a NSF AGS Postdoctoral Fellowship. Taina Yli-Juuti was supported by the Academy of Finland Centre of Excellence (grant no. 272041) and strategic funding from University of Eastern Finland.

Edited by: A. Laskin

Reviewed by: four anonymous referees

\section{References}

Almeida, J., Schobesberger, S., Kurten, A., Ortega, I. K., Kupiainen-Maatta, O., Praplan, A. P., Adamov, A., Amorim, A., Bianchi, F., Breitenlechner, M., David, A., Dommen, J., Donahue, N. M., Downard, A., Dunne, E., Duplissy, J., Ehrhart, S., Flagan, R. C., Franchin, A., Guida, R., Hakala, J., Hansel, A., Heinritzi, M., Henschel, H., Jokinen, T., Junninen, H., Kajos, M., Kangasluoma, J., Keskinen, H., Kupc, A., Kurten, T., Kvashin, A. N., Laaksonen, A., Lehtipalo, K., Leiminger, M., Leppa, J., Loukonen, V., Makhmutov, V., Mathot, S., McGrath, M. J., Nieminen, T., Olenius, T., Onnela, A., Petaja, T., Riccobono, F., Riipinen, I., Rissanen, M., Rondo, L., Ruuskanen, T., Santos, F. D., Sarnela, N., Schallhart, S., Schnitzhofer, R., Seinfeld, J. H., Simon, M., Sipila, M., Stozhkov, Y., Stratmann, F., Tome, A., Trostl, J., Tsagkogeorgas, G., Vaattovaara, P., Viisanen, Y., Virtanen, A., Vrtala, A., Wagner, P. E., Weingartner, E., Wex, H., Williamson, C., Wimmer, D., Ye, P., Yli-Juuti, T., Carslaw, K. S., Kulmala, M., Curtius, J., Baltensperger, U., Worsnop, D. R., Vehkamaki, H., and Kirkby, J.: Molecular understanding of sulphuric acid-amine particle nucleation in the atmosphere, Nature, 502, 359-363, doi:10.1038/nature12663, 2013.

Barsanti, K. C. and Pankow, J. F.: Thermodynamics of the formation of atmospheric organic particulate matter by accretion reactions - Part 1: aldehydes and ketones, Atmos. Environ., 38, 4371-4382, doi:10.1016/j.atmosenv.2004.03.035, 2004.

Barsanti, K. C. and Pankow, J. F.: Thermodynamics of the formation of atmospheric organic particulate matter by accretion reactions - 2. Dialdehydes, methylglyoxal, and diketones, Atmos. Environ., 39, 6597-6607, doi:10.1016/j.atmosenv.2005.07.056, 2005.

Barsanti, K. C. and Pankow, J. F.: Thermodynamics of the formation of atmospheric organic particulate matter by accretion reactions - Part 3: Carboxylic and dicarboxylic acids, Atmos. Environ., 40, 6676-6686, doi:10.1016/j.atmosenv.2006.03.013, 2006.
Barsanti, K. C., McMurry, P. H., and Smith, J. N.: The potential contribution of organic salts to new particle growth, Atmos. Chem. Phys., 9, 2949-2957, doi:10.5194/acp-9-2949-2009, 2009.

Bilde, M., Barsanti, K., Booth, M., Cappa, C. D., Donahue, N. M., Emanuelsson, E. U., McFiggans, G., Krieger, U. K., Marcolli, C., Topping, D., Ziemann, P., Barley, M., Clegg, S., Dennis-Smither, B., Hallquist, M., Hallquist, Å. M., Khlystov, A., Kulmala, M., Mogensen, D., Percival, C. J., Pope, F., Reid, J. P., Ribeiro da Silva, M. A. V, Rosenoern, T., Salo, K., Soonsin, V. P., Yli-Juuti, T., Prisle, N. L., Pagels, J., Rarey, J., Zardini, A. A., and Riipinen, I.: Saturation vapor pressures and transition enthalpies of low-volatility organic molecules of atmospheric relevance: from dicarboxylic acids to complex mixtures., Chem. Rev., 115, 411556, doi:10.1021/cr5005502, 2015.

Boucher, O., Randall, D., Artaxo, P., Bretherton, C., Feingold, G., Forster, P., Kerminen, V.M., Kondo, Y., Liao, H., Lohmann, U., Rasch, P., Satheesh, S. K., Sherwood, S., Stevens, B., and Zhang, X. Y.: Clouds and Aerosols, in: Climate Change 2013: The Physical Science Basis. Contribution of Working Group I to the Fifth Assessment Report of the Intergovernmental Panel on Climate Change, edited by: Stocker, T. F., Qin, D., Plattner, G. K., Tignor, M., Allen, S. K., Boschung, J., Nauels, A., Xia, Y., Bex, V., and Midgley, P. M., Cambridge University Press, Cambridge, UK, and New York, NY, USA, 2013.

Bzdek, B. R., Lawler, M. J., Horan, A. J., Pennington, M. R.,. DePalma, J. W, Zhao, J., Smith, J. N., and Johnston, M. V.: Molecular constraints on particle growth during new particle formation, Geophys. Res. Lett., 41, 6045-6054, doi:10.1002/2014GL060160, 2014.

Bzdek, B. R., Zordan, C. A., Pennington, M. R., Luther III, G. W., and Johnston, M. V: Quantitative Assessment of the Sulfuric Acid Contribution to New Particle Growth, Environ. Sci. Technol., 46, 4365-4373, doi:10.1021/es204556c, 2012.

Carlton, A. G., Bhave, P. V, Napelenok, S. L., Edney, E. O., Sarwar, G., Pinder, R. W., Pouliot, G. A., and Houyoux, M.: Model representation of secondary organic aerosol in CMAQv4.7., Environ. Sci. Technol., 44, 8553-8560, doi:10.1021/es100636q, 2010.

Campaign: New Particle Formation Study 2013 (NPFS 2013), available at: http://www.arm.gov/campaigns/sgp2013npfs, last access: February 2016.

Charlson, R. J., Schwartz, S. E., Hales, J. M., Cess, R. D., Coakley, J. A., Hansen, J. E., and Hofmann, D. J.: Climate forcing by anthropogenic aerosols, Science, 255, 423-430, 1992.

Chen, M., Titcombe, M., Jiang, J., Jen, C., Kuang, C., Fischer, M. L., Eisele, F. L., Siepmann, J. I., Hanson, D. R., Zhao, J., and McMurry, P. H.: Acid-base chemical reaction model for nucleation rates in the polluted atmospheric boundary layer, P. Natl. Acad. Sci. USA, 109, 18713-18718, doi:10.1073/pnas.1210285109, 2012.

Chen, M., Titcombe, M., Jiang, J., Jen, C., Kuang, C., Fischer, M. L., Eisele, F. L., Siepmann, J. I., Hanson, D. R., Zhao, J., and McMurry, P. H.: Acid-base chemical reaction model for nucleation rates in the polluted atmospheric boundary layer, AIP Conf. Proc., 1527, 647-650, doi:10.1063/1.4803354, 2013.

Clegg, S. L. and Seinfeld, J. H.: Thermodynamic models of aqueous solutions containing inorganic electrolytes and dicarboxylic acids at $298.15 \mathrm{~K}$. 1. The acids as non-dissociating components, J. Phys. Chem. A, 110, 5692-5717, 2006a. 
Clegg, S. L. and Seinfeld, J. H.: Thermodynamic models of aqueous solutions containing inorganic electrolytes and dicarboxylic acids at 298.15 K. 2. Systems including dissociation equilibria, J. Phys. Chem. A, 110, 5718-5734, 2006b.

Clegg, S. L., Pitzer, K. S., and Brimblecombe, P.: Thermodynamics of Multicomponent, Misclble, Ionic Solutions. 2. Mixtures Including Unsymmetrical Electrolytes, J. Phys. Chem., 96, 94709479, doi:10.1021/j100202a074, 1992.

Clegg, S. L., Brimblecombe, P., and Wexler, A. S.: Extended AIM Aerosol Thermodynamics model, available at: http://www.aim. env.uea.ac.uk/aim/aim.php, last access: February 2016.

Clement, A. C., Burgman, R., and Norris, J. R.: Observational and Model Evidence for Positive Low-Level Cloud Feedback, Science, 325, 460-464, 2009.

D’Andrea, S. D., Häkkinen, S. A. K., Westervelt, D. M., Kuang, C., Levin, E. J. T., Kanawade, V. P., Leaitch, W. R., Spracklen, D. V., Riipinen, I., and Pierce, J. R.: Understanding global secondary organic aerosol amount and size-resolved condensational behavior, Atmos. Chem. Phys., 13, 11519-11534, doi:10.5194/acp-1311519-2013, 2013

Donahue, N. M., Trump, E. R., Pierce, J. R., and Riipinen, I.: Theoretical constraints on pure vapor-pressure driven condensation of organics to ultrafine particles, Geophys. Res. Lett., 38, L16801, doi:10.1029/2011GL048115, 2011.

Draxler, R. R. and Rolph, G. D.: HYSPLIT (HYbrid Single-Particle Lagrangian Integrated Trajectory) Model access via NOAA ARL READYWebsite, NOAA Air Resources Laboratory, Silver Spring, MD, 2012.

Ehn, M., Kleist, E., Junninen, H., Petäjä, T., Lönn, G., Schobesberger, S., Dal Maso, M., Trimborn, A., Kulmala, M., Worsnop, D. R., Wahner, A., Wildt, J., and Mentel, Th. F.: Gas phase formation of extremely oxidized pinene reaction products in chamber and ambient air, Atmos. Chem. Phys., 12, 5113-5127, doi:10.5194/acp-12-5113-2012, 2012.

Ehn, M., Thornton, J. A., Kleist, E., Sipilä, M., Junninen, H., Pullinen, I., Springer, M., Rubach, F., Tillmann, R., Lee, B., LopezHilfiker, F., Andres, S., Acir, I.-H., Rissanen, M., Jokinen, T., Schobesberger, S., Kangasluoma, J., Kontkanen, J., Nieminen, T., Kurtén, T., Nielsen, L. B., Jørgensen, S., Kjaergaard, H. G., Canagaratna, M., Maso, M. D., Berndt, T., Petäjä, T., Wahner, A., Kerminen, V.-M., Kulmala, M., Worsnop, D. R., Wildt, J., and Mentel, T. F.: A large source of low-volatility secondary organic aerosol., Nature, 506, 476-479, doi:10.1038/nature13032, 2014.

Eisele, F. L. and Tanner, D. J.: Measurement of the gas phase concentration of $\mathrm{H} 2 \mathrm{SO} 4$ and methane sulfonic acid and estimates of $\mathrm{H}_{2} \mathrm{SO}_{4}$ production and loss in the atmosphere, J. Geophys. Res., 98, 9001, doi:10.1029/93JD00031, 1993.

Ervens, B. and Volkamer, R.: Glyoxal processing by aerosol multiphase chemistry: towards a kinetic modeling framework of secondary organic aerosol formation in aqueous particles, Atmos. Chem. Phys., 10, 8219-8244, doi:10.5194/acp-10-8219-2010, 2010.

Forster, P., Ramaswamy, V., Artaxo, P., Berntsen, T., Betts, R., Fahey, D. W., Haywood, J., Lean, J., Lowe, D. C., Myhre, G., Nganga, J., Prinn, R., Raga, G., Schulz, M., and Dorland, R. V.: Changes in atmospheric constituents and in radiative forcing, in: Climate Change 2007: The Physical Science Basis. Contribution of Working Group I to the Fourth Assessment Report of the In- tergovernmental Panel on Climate Change, edited by: Solomon, S., Qin, D., Manning, M., Chen, Z., Marquis, M.,Averyt, K. B., Tignor, M., and Miller, H. L., Cambridge University Press, Cambridge, UK and New York, NY, USA, 129-234, 2007.

Freshour, N. A., Carlson, K. K., Melka, Y. A., Hinz, S., Panta, B., and Hanson, D. R.: Amine permeation sources characterized with acid neutralization and sensitivities of an amine mass spectrometer, Atmos. Meas. Tech., 7, 3611-3621, doi:10.5194/amt7-3611-2014, 2014.

Gao, S., Keywood, M., Ng, N. L., Surratt, J., Varutbangkul, V., Bahreini, R., Flagan, R. C., and Seinfeld, J. H.: Low-MolecularWeight and Oligomeric Components in Secondary Organic Aerosol from the Ozonolysis of Cycloalkenes and $\alpha$-Pinene, J. Phys. Chem. A, 108, 10147-10164, doi:10.1021/jp047466e, 2004.

Ge, X., Wexler, A. S., and Clegg, S. L.: Atmospheric amines - Part I. A review, Atmos. Environ., 45, 524-546, doi:10.1016/j.atmosenv.2010.10.012, 2011.

GEOS-Chem Model: http://geos-chem.org, last access: February 2016.

Grosjean, D., Van Cauwenberghe, K., Schmid, J. P., Kelley, P. E., and Pitts, J. N.: Identification of C3-C10 aliphatic dicarboxylic acids in airborne particulate matter, Environ. Sci. Technol., 12, 313-317, doi:10.1021/es60139a005, 1978.

Guenther, A., Karl, T., Harley, P., Wiedinmyer, C., Palmer, P. I., and Geron, C.: Estimates of global terrestrial isoprene emissions using MEGAN (Model of Emissions of Gases and Aerosols from Nature), Atmos. Chem. Phys., 6, 3181-3210, doi:10.5194/acp-63181-2006, 2006.

Guenther, A. B., Jiang, X., Heald, C. L., Sakulyanontvittaya, T., Duhl, T., Emmons, L. K., and Wang, X.: The Model of Emissions of Gases and Aerosols from Nature version 2.1 (MEGAN2.1): an extended and updated framework for modeling biogenic emissions, Geosci. Model Dev., 5, 1471-1492, doi:10.5194/gmd-51471-2012, 2012.

Haar, L. and Gallagher, J. S.: Thermodynamic properties of ammonia, J. Phys. Chem., 7, 635-792, doi:10.1063/1.3159398, 1978.

Hall, W. A. and Johnston, M. V.: Oligomer Content of $\alpha$-Pinene Secondary Organic Aerosol, Aerosol Sci. Technol., 45, 37-45, doi:10.1080/02786826.2010.517580, 2011.

Hanson, D. R., McMurry, P. H., Jiang, J., Tanner, D., and Huey, L. G.: Ambient pressure proton transfer mass spectrometry: detection of amines and ammonia., Environ. Sci. Technol., 45, 88818888, doi:10.1021/es201819a, 2011.

Heaton, K. J., Dreyfus, M. A., Wang, S., and Johnston, M. V: Oligomers in the early stage of biogenic secondary organic aerosol formation and growth, Environ. Sci. Technol., 41, 61296136, doi:10.1021/es070314n, 2007.

Iida, K., Stolzenburg, M. R., McMurry, P. H., and Smith, J. N.: Estimating nanoparticle growth rates from size-dependent charged fractions: Analysis of new particle formation events in Mexico City, J. Geophys. Res.-Atmos., 113, 897-901, doi:10.1029/2007JD009260, 2008.

International Union of Pure and Applied Chemistry: http://www. iupac.org/, last access: February 2016.

Jaeschke, W., Dierssen, J. P., Gunther, A., and Schumann, M.: Phase partitioning of ammonia and ammonium in a multiphase system studied using a new vertical wet denuder technique, Atmos. Environ., 32, 365-371, 1998. 
Jen, C. N., Bachman, R., Zhao, J., McMurry, P. H., and Hanson, D. R.: Diamine-sulfuric acid reactions are a potent source of new particle formation, Geophys. Res. Lett., 43, 867-873, doi:10.1002/2015GL066958, 2015.

Jiang, J., Chen, M., Kuang, C., Attoui, M., and McMurry, P. H.: Electrical Mobility Spectrometer Using a Diethylene Glycol Condensation Particle Counter for Measurement of Aerosol Size Distributions Down to $1 \mathrm{~nm}$, Aerosol Sci. Technol., 45, 510-521, doi:10.1080/02786826.2010.547538, 2011.

Jokinen, T., Sipilä, M., Richters, S., Kerminen, V.-M., Paasonen, P., Stratmann, F., Worsnop, D., Kulmala, M., Ehn, M., Herrmann, H., and Berndt, T.: Rapid Autoxidation Forms Highly Oxidized $\mathrm{RO}_{2}$ Radicals in the Atmosphere, Angew. Chemie Int. Ed., 53, 14596-14600, doi:10.1002/anie.201408566, 2014.

Jokinen, T., Berndt, T., Makkonen, R., Kerminen, V., Junninen, H., and Paasonen, P.: Production of extremely low volatile organic compounds from biogenic emissions?: Measured yields and atmospheric implications, P. Natl. Acad. Sci. USA, 112, 71237128, doi:10.1073/pnas.1423977112, 2015.

Kalberer, M., Paulsen, D., Sax, M., Steinbacher, M., Dommen, J., Prevot, A. S. H., Fisseha, R., Weingartner, E., Frankevich, V., Zenobi, R., and Baltensperger, U.: Identification of polymers as major components of atmospheric organic aerosols., Science, 303, 1659-1662, doi:10.1126/science.1092185, 2004.

Kawamura, K. and Ikushima, K.: Seasonal changes in the distribution of dicarboxylic acids in the urban atmosphere, Environ. Sci. Technol., 27, 2227-2235, 1993.

Kawamura, K. and Sakaguchi, F.: Molecular distributions of water soluble dicarboxylic acids in marine aerosols over the Pacific Ocean including tropics, J. Geophys. Res. A, 104, 3501-3509, 1999.

Kawamura, K., Kasukabe, H., Yasui, O., and Barrie, L. A.: Production of dicarboxylic acids in the arctic atmosphere at polar sunrise, Geophys. Res. Lett., 22, 1253-1256, 1995.

Kawamura, K., Seméré, R., Imai, Y., Fujii, Y., and Hayashi, M.: Water soluble dicarboxylic acids and related compounds in Antarctic aerosols, J. Geophys. Res., 101, 18721, doi:10.1029/96JD01541, 1996.

Kerminen, V.-M., Ojanen, C., Pakkanen, T., Hillamo, R., Aurela, M., and Meriläinen, J.: Low-Molecular-Weight Dicarboxylic Acids in an Urban and Rural Atmosphere, J. Aerosol Sci., 31, 349-362, doi:10.1016/S0021-8502(99)00063-4, 2000.

Kerminen, V. M., Lehtinen, K. E. J., Anttila, T., and Kulmala, M.: Dynamics of atmospheric nucleation mode particles: a timescale analysis, Tellus B, 56, 135-146, 2004.

Khwaja, H. A.: Atmospheric concentrations of carboxylic acids and related compounds at a semiurban site, Atmos. Environ., 29, 127-139, doi:10.1016/1352-2310(94)00211-3, 1995.

Kirkby, J., Curtius, J., Almeida, J., Dunne, E., Duplissy, J., Ehrhart, S., Franchin, A., Gagne, S., Ickes, L., Kurten, A., Kupc, A., Metzger, A., Riccobono, F., Rondo, L., Schobesberger, S., Tsagkogeorgas, G., Wimmer, D., Amorim, A., Bianchi, F., Breitenlechner, M., David, A., Dommen, J., Downard, A., Ehn, M., Flagan, R. C., Haider, S., Hansel, A., Hauser, D., Jud, W., Junninen, H., Kreissl, F., Kvashin, A., Laaksonen, A., Lehtipalo, K., Lima, J., Lovejoy, E. R., Makhmutov, V., Mathot, S., Mikkila, J., Minginette, P., Mogo, S., Nieminen, T., Onnela, A., Pereira, P., Petaja, T., Schnitzhofer, R., Seinfeld, J. H., Sipila, M., Stozhkov, Y., Stratmann, F., Tome, A., Vanhanen, J., Viisanen, Y., Vrtala,
A., Wagner, P. E., Walther, H., Weingartner, E., Wex, H., Winkler, P. M., Carslaw, K. S., Worsnop, D. R., Baltensperger, U., and Kulmala, M.: Role of sulphuric acid, ammonia and galactic cosmic rays in atmospheric aerosol nucleation, Nature, 476, 429-433 doi:10.1038/nature10343, 2011.

Kuang, C., McMurry, P. H., and McCormick, A. V.: Determination of cloud condensation nuclei production from measured new particle formation events, Geophys. Res. Lett., 36, L09822, doi:10.1029/2009GL037584, 2009.

Kuang, C., Riipinen, I., Sihto, S.-L., Kulmala, M., McCormick, A. V., and McMurry, P. H.: An improved criterion for new particle formation in diverse atmospheric environments, Atmos. Chem. Phys., 10, 8469-8480, doi:10.5194/acp-10-8469-2010, 2010.

Kulmala, M., Vehkamäki, H., Petäjä, T., Dal Maso, M., Lauri, A., Kerminen, V.-M., Birmili, W., and McMurry, P. H.: Formation and growth rates of ultrafine atmospheric particles: a review of observations, J. Aerosol Sci., 35, 143-176, doi:10.1016/j.jaerosci.2003.10.003, 2004.

Lawler, M. J., Whitehead, J., O'Dowd, C., Monahan, C., McFiggans, G., and Smith, J. N.: Composition of 15-85 nm particles in marine air, Atmos. Chem. Phys., 14, 11557-11569, doi:10.5194/acp-14-11557-2014, 2014.

Lehtipalo, K., Leppä, J., Kontkanen, J., Kangasluoma, J., Franchin, A., Wimmer, D., Schobesberger, S., Junninen, H., Petäjä, T., Sipilä, M., Mikkilä, J., Vanhanen, J., Worsnop, D. R., and Kulmala, M.: Methods for determining particle size distribution and growth rates between 1 and $3 \mathrm{~nm}$ using the Particle Size Magnifier, Boreal Env. Res., 19 (suppl. B), 215-236, 2014.

Limbeck, A. and Puxbaum, H.: Organic acids in continental background aerosols, Atmos. Environ., 33, 1847-1852, doi:10.1016/S1352-2310(98)00347-1, 1999.

Limbeck, A., Kulmala, M., and Puxbaum, H.: Secondary organic aerosol formation in the atmosphere via heterogeneous reaction of gaseous isoprene on acidic particles, Geophys. Res. Lett., 30, 4-7, doi:10.1029/2003GL017738, 2003.

Mäkelä, J., Yli-Koivisto, S., and Hiltunen, V.: Chemical composition of aerosol during particle formation events in boreal forest, Tellus B, 380-393, doi:10.1034/j.1600-0889.2001.530405.x, 2001.

Marti, J. J., Jefferson, A., Cai, X. P., Richert, C., McMurry, P. H., and Eisele, F.: $\mathrm{H}_{2} \mathrm{SO}_{4}$ vapor pressure of sulfuric acid and ammonium sulfate solutions, J. Geophys. Res.-Atmos., 102, 37253735, doi:10.1029/96JD03064, 1997.

Matsunaga, S. N., Wiedinmyer, C., Guenther, A. B., Orlando, J. J., Karl, T., Toohey, D. W., Greenberg, J. P., and Kajii, Y.: Isoprene oxidation products are a significant atmospheric aerosol component, Atmos. Chem. Phys. Discuss., 5, 11143-11156, doi:10.5194/acpd-5-11143-2005, 2005.

Mochida, M., Kawabata, A., Kawamura, K., Hatsushika, H., and Yamazaki, K.: Seasonal variation and origins of dicarboxylic acids in the marine atmosphere over the western North Pacific, J. Geophys. Res. A, 108, AAC7/1-AAC7/11, 2003.

Murphy, B. N., Donahue, N. M., Robinson, A. L., and Pandis, S. N.: A naming convention for atmospheric organic aerosol, Atmos. Chem. Phys., 14, 5825-5839, doi:10.5194/acp-14-58252014, 2014.

Narukawa, M., Kawamura, K., Li, S. M., and Bottenheim, J. W.: Dicarboxylic acids in the Arctic aerosols and snowpacks collected during ALERT 2000, Atmos. Environ., 36, 2491-2499, 2002. 
Ortega, J., Turnipseed, A., Guenther, A. B., Karl, T. G., Day, D. A., Gochis, D., Huffman, J. A., Prenni, A. J., Levin, E. J. T., Kreidenweis, S. M., DeMott, P. J., Tobo, Y., Patton, E. G., Hodzic, A., Cui, Y. Y., Harley, P. C., Hornbrook, R. S., Apel, E. C., Monson, R. K., Eller, A. S. D., Greenberg, J. P., Barth, M. C., CampuzanoJost, P., Palm, B. B., Jimenez, J. L., Aiken, A. C., Dubey, M. K., Geron, C., Offenberg, J., Ryan, M. G., Fornwalt, P. J., Pryor, S. C., Keutsch, F. N., DiGangi, J. P., Chan, A. W. H., Goldstein, A. H., Wolfe, G. M., Kim, S., Kaser, L., Schnitzhofer, R., Hansel, A., Cantrell, C. A., Mauldin, R. L., and Smith, J. N.: Overview of the Manitou Experimental Forest Observatory: site description and selected science results from 2008 to 2013, Atmos. Chem. Phys., 14, 6345-6367, doi:10.5194/acp-14-6345-2014, 2014.

Pankow, J. F.: Gas/particle partitioning of neutral and ionizing compounds to single and multi-phase aerosol particles. 1. Unified modeling framework, Atmos. Environ., 37, 3323-3333, 2003.

Pennington, M. R. and Johnston, M. V.: Trapping charged nanoparticles in the nano aerosol mass spectrometer (NAMS), Int. J. Mass Spectrom., 311, 64-71, doi:10.1016/j.ijms.2011.12.011, 2012

Pierce, J. R. and Adams, P. J.: Efficiency of cloud condensation nuclei formation from ultrafine particles, Atmos. Chem. Phys., 7, 1367-1379, doi:10.5194/acp-7-1367-2007, 2007.

Pierce, J. R. and Adams, P. J.: Uncertainty in global CCN concentrations from uncertain aerosol nucleation and primary emission rates, Atmos. Chem. Phys., 9, 1339-1356, doi:10.5194/acp-91339-2009, 2009.

Pierce, J. R., Riipinen, I., Kulmala, M., Ehn, M., Petäjä, T., Junninen, H., Worsnop, D. R., and Donahue, N. M.: Quantification of the volatility of secondary organic compounds in ultrafine particles during nucleation events, Atmos. Chem. Phys., 11, 90199036, doi:10.5194/acp-11-9019-2011, 2011.

Pierce, J. R., Leaitch, W. R., Liggio, J., Westervelt, D. M., Wainwright, C. D., Abbatt, J. P. D., Ahlm, L., Al-Basheer, W., Cziczo, D. J., Hayden, K. L., Lee, A. K. Y., Li, S.-M., Russell, L. M., Sjostedt, S. J., Strawbridge, K. B., Travis, M., Vlasenko, A., Wentzell, J. J. B., Wiebe, H. A., Wong, J. P. S., and Macdonald, A. M.: Nucleation and condensational growth to $\mathrm{CCN}$ sizes during a sustained pristine biogenic SOA event in a forested mountain valley, Atmos. Chem. Phys., 12, 3147-3163, doi:10.5194/acp-12-3147-2012, 2012.

Pinder, R. W., Adams, P. J., and Pandis, S. N.: Ammonia emission controls as a cost-effective strategy for reducing atmospheric particulate matter in the eastern United States, Environ. Sci. Technol., 41, 380-386, 2007.

Poling, B. E., Prausnitz, J. M., and O'Connell, J. P.: Properties of gases and liquids, 5th Edn., McGraw-Hill, New York, 2001.

Pöschl, U., Rudich, Y., and Ammann, M.: Kinetic model framework for aerosol and cloud surface chemistry and gas-particle interactions - Part 1: General equations, parameters, and terminology, Atmos. Chem. Phys., 7, 5989-6023, doi:10.5194/acp-75989-2007, 2007.

Poling, B. E., Prausnitz, J. M., and O'Connell, J. P.: Properties of gases and liquids, 5th Edn., McGraw-Hill, New York, 2001.

Pun, B. K. and Seigneur, C.: Investigative modeling of new pathways for secondary organic aerosol formation, Atmos. Chem. Phys., 7, 2199-2216, doi:10.5194/acp-7-2199-2007, 2007.

Riccobono, F., Schobesberger, S., Scott, C. E., Dommen, J., Ortega, I. K., Rondo, L., Almeida, J., Amorim, A., Bianchi, F., Breiten- lechner, M., David, A., Downard, A., Dunne, E. M., Duplissy, J., Ehrhart, S., Flagan, R. C., Franchin, A., Hansel, A., Junninen, H., Kajos, M., Keskinen, H., Kupc, A., Kurten, A., Kvashin, A. N., Laaksonen, A., Lehtipalo, K., Makhmutov, V., Mathot, S., Nieminen, T., Onnela, A., Petaja, T., Praplan, A. P., Santos, F. D., Schallhart, S., Seinfeld, J. H., Sipila, M., Spracklen, D. V., Stozhkov, Y., Stratmann, F., Tome, A., Tsagkogeorgas, G., Vaattovaara, P., Viisanen, Y., Vrtala, A., Wagner, P. E., Weingartner, E., Wex, H., Wimmer, D., Carslaw, K. S., Curtius, J., Donahue, N. M., Kirkby, J., Kulmala, M., Worsnop, D. R., and Baltensperger, U.: Oxidation Products of Biogenic Emissions Contribute to Nucleation of Atmospheric Particles, Science, 344, 717-721, doi:10.1126/science.1243527, 2014.

Riipinen, I., Sihto, S.-L., Kulmala, M., Arnold, F., Dal Maso, M., Birmili, W., Saarnio, K., Teinilä, K., Kerminen, V.-M., Laaksonen, A., and Lehtinen, K. E. J.: Connections between atmospheric sulphuric acid and new particle formation during QUEST III-IV campaigns in Heidelberg and Hyytiälä, Atmos. Chem. Phys., 7, 1899-1914, doi:10.5194/acp-7-1899-2007, 2007.

Riipinen, I., Pierce, J. R., Yli-Juuti, T., Nieminen, T., Häkkinen, S., Ehn, M., Junninen, H., Lehtipalo, K., Petäjä, T., Slowik, J., Chang, R., Shantz, N. C., Abbatt, J., Leaitch, W. R., Kerminen, V.-M., Worsnop, D. R., Pandis, S. N., Donahue, N. M., and Kulmala, M.: Organic condensation: a vital link connecting aerosol formation to cloud condensation nuclei (CCN) concentrations, Atmos. Chem. Phys., 11, 3865-3878, doi:10.5194/acp-11-38652011, 2011.

Riipinen, I., Yli-Juuti, T., Pierce, J. R., Petäjä, T., Worsnop, D. R., Kulmala, M., and Donahue, N. M.: The contribution of organics to atmospheric nanoparticle growth, Nat. Geosci., 5, 453-458, doi:10.1038/ngeo1499, 2012.

Rissanen, M. P., Kurtén, T., Sipilä, M., Thornton, J. A., Kangasluoma, J., Sarnela, N., Junninen, H., Jørgensen, S., Schallhart, S., Kajos, M. K., Taipale, R., Springer, M., Mentel, T. F., Ruuskanen, T., Petäjä, T., Worsnop, D. R., Kjaergaard, H. G., and Ehn, M.: The formation of highly oxidized multifunctional products in the ozonolysis of cyclohexene., J. Am. Chem. Soc., 136, 1559616606, doi:10.1021/ja507146s, 2014.

Rogge, W. F.,Mazurek, M. A., Hildemann, L. M., Cass, G. R., and Simoneit, B. R. T.: Quantification of urban organic aerosols at a molecular level: identification, abundance and seasonal variation, Atmos. Environ. Part A, 27A, 8, 1309-1330, 1993.

Rolph, G. D.: Real-time Environmental Applications and Display sYstem (READY), NOAA Air Resources Laboratory, Silver Spring, MD, 2012.

Rosenfeld, D., Lohmann, U., Raga, G. B., O’Dowd, C. D., Kulmala, M., Fuzzi, S., Reissell, A., and Andreae, M. O.: Flood or Drought: How Do Aerosols Affect Precipitation?, Science, 312, 1309-1313, 2008.

Scott, C. E., Spracklen, D. V., Pierce, J. R., Riipinen, I., D’Andrea, S. D., Rap, A., Carslaw, K. S., Forster, P. M., Artaxo, P., Kulmala, M., Rizzo, L. V., Swietlicki, E., Mann, G. W., and Pringle, K. J.: Impact of gas-to-particle partitioning approaches on the simulated radiative effects of biogenic secondary organic aerosol, Atmos. Chem. Phys., 15, 12989-13001, doi:10.5194/acp-1512989-2015, 2015.

Seinfeld, J. H. and Pandis, S. N.: Atmospheric chemistry and physics: From air pollution to climate change, John Wiley \& Sons, Inc., New York, USA, 523-538, 1998. 
Seinfeld, J. H. and Pandis, S. N.: Atmospheric Chemistry and Physics, 2nd ed., John Wiley and Sons, New York, 2006.

Sempére, R. and Kawamura, K.: Comparative distributions of dicarboxylic acids and related polar compounds in snow, rain and aerosols from urban atmosphere, Atmos. Environ., 28, 449-459, doi:10.1016/1352-2310(94)90123-6, 1994.

Sempére, R. and Kawamura, K.: Trans-hemispheric contribution of C2-C10 a, w-dicarboxylic acids, and related polar compounds to water-soluble organic carbon in the western Pacific aerosols in relation to photochemical oxidation reactions, Glob. Biogeochem. Cy., 17, 38/1-38/15, 2003.

Shiraiwa, M., Garland, R. M., and Pöschl, U.: Kinetic double-layer model of aerosol surface chemistry and gas-particle interactions (K2-SURF): Degradation of polycyclic aromatic hydrocarbons exposed to $\mathrm{O}_{3}, \mathrm{NO}_{2}, \mathrm{H}_{2} \mathrm{O}, \mathrm{OH}$ and $\mathrm{NO}_{3}$, Atmos. Chem. Phys., 9, 9571-9586, doi:10.5194/acp-9-9571-2009, 2009.

Shiraiwa, M., Pfrang, C., and Pöschl, U.: Kinetic multi-layer model of aerosol surface and bulk chemistry (KM-SUB): the influence of interfacial transport and bulk diffusion on the oxidation of oleic acid by ozone, Atmos. Chem. Phys., 10, 3673-3691, doi:10.5194/acp-10-3673-2010, 2010.

Shiraiwa, M., Pfrang, C., Koop, T., and Pöschl, U.: Kinetic multilayer model of gas-particle interactions in aerosols and clouds (KM-GAP): linking condensation, evaporation and chemical reactions of organics, oxidants and water, Atmos. Chem. Phys., 12, 2777-2794, doi:10.5194/acp-12-2777-2012, 2012.

Sindelarova, K., Granier, C., Bouarar, I., Guenther, A., Tilmes, S., Stavrakou, T., Müller, J.-F., Kuhn, U., Stefani, P., and Knorr, W.: Global data set of biogenic VOC emissions calculated by the MEGAN model over the last 30 years, Atmos. Chem. Phys., 14, 9317-9341, doi:10.5194/acp-14-9317-2014, 2014.

Smith, J. N. and Rathbone, G. J.: Carboxylic acid characterization in nanoparticles by thermal desorption chemical ionization mass spectrometry, Int. J. Mass Spectrom., 274, 8-13, doi:10.1016/j.ijms.2008.04.008, 2008.

Smith, J. N., Moore, K. F., McMurry, P. H., and Eisele, F. L.: Atmospheric Measurements of Sub-20 nm Diameter Particle Chemical Composition by Thermal Desorption Chemical Ionization Mass Spectrometry, Aerosol Sci. Technol., 38, 100-110, doi:10.1080/02786820490249036, 2004.

Smith, J. N., Dunn, M. J., VanReken, T. M., Iida, K., Stolzenburg, M. R., McMurry, P. H., and Huey, L. G.: Chemical composition of atmospheric nanoparticles formed from nucleation in Tecamac, Mexico: Evidence for an important role for organic species in nanoparticle growth, Geophys. Res. Lett., 35, 2-6, doi:10.1029/2007GL032523, 2008.

Smith, J. N., Barsanti, K. C., Friedli, H. R., Ehn, M., Kulmala, M., Collins, D. R., Scheckman, J. H., Williams, B. J., and McMurry, P. H.: Observations of aminium salts in atmospheric nanoparticles and possible climatic implications, P. Natl. Acad. Sci. USA, 107, 6634-6639, doi:10.1073/pnas.0912127107, 2010.

Southern Great Plains: http://www.arm.gov/sites/sgp, last access: February 2016.

Spracklen, D. V., Carslaw, K. S., Kulmala, M., Kerminen, V.-M., Sihto, S.-L., Riipinen, I., Merikanto, J., Mann, G. W., Chipperfield, M. P., Wiedensohler, A., Birmili, W., and Lihavainen, H.: Contribution of particle formation to global cloud condensation nuclei concentrations, Geophys. Res. Lett., 35, L06808, doi:10.1029/2007GL033038, 2008.
Spracklen, D. V., Carslaw, K. S., Merikanto, J., Mann, G. W., Reddington, C. L., Pickering, S., Ogren, J. A., Andrews, E., Baltensperger, U., Weingartner, E., Boy, M., Kulmala, M., Laakso, L., Lihavainen, H., Kivekäs, N., Komppula, M., Mihalopoulos, N., Kouvarakis, G., Jennings, S. G., O’Dowd, C., Birmili, W., Wiedensohler, A., Weller, R., Gras, J., Laj, P., Sellegri, K., Bonn, B., Krejci, R., Laaksonen, A., Hamed, A., Minikin, A., Harrison, R. M., Talbot, R., and Sun, J.: Explaining global surface aerosol number concentrations in terms of primary emissions and particle formation, Atmos. Chem. Phys., 10, 4775-4793, doi:10.5194/acp-10-4775-2010, 2010.

Spracklen, D. V., Jimenez, J. L., Carslaw, K. S., Worsnop, D. R., Evans, M. J., Mann, G. W., Zhang, Q., Canagaratna, M. R., Allan, J., Coe, H., McFiggans, G., Rap, A., and Forster, P.: Aerosol mass spectrometer constraint on the global secondary organic aerosol budget, Atmos. Chem. Phys., 11, 12109-12136, doi:10.5194/acp-11-12109-2011, 2011.

Stolzenburg, M. R., McMurry, P. H., Sakurai, H., Smith, J. N., Mauldin, R. L., Eisele, F. L., and Clement, C. F.: Growth rates of freshly nucleated atmospheric particles in Atlanta, J. Geophys. Res., 110, D22S05, doi:10.1029/2005JD005935, 2005.

Tao, Y., Ye, X., Jiang, S., Yang, X., Chen, J., Xie, Y., and Wang, R.: Effects of amines on particle growth observed in new particle formation events, J. Geophys. Res.-Atmos., 121, 324-335, doi:10.1002/2015JD024245, 2016.

Tolocka, M. P., Jang, M., Ginter, J. M., Cox, F. J., Kamens, R. M., and Johnston, M. V: Formation of oligomers in secondary organic aerosol, Environ. Sci. Technol., 38, 1428-1434, doi:10.1021/es035030r, 2004.

Virtanen, A., Joutsensaari, J., Koop, T., Kannosto, J., Yli-Pirilä, P., Leskinen, J., Mäkelä, J. M., Holopainen, J. K., Pöschl, U., Kulmala, M., Worsnop, D. R., and Laaksonen, A.: An amorphous solid state of biogenic secondary organic aerosol particles, Nature, 467, 824-827, doi:10.1038/nature09455, 2010.

Virtanen, A., Kannosto, J., Kuuluvainen, H., Arffman, A., Joutsensaari, J., Saukko, E., Hao, L., Yli-Pirilä, P., Tiitta, P., Holopainen, J. K., Keskinen, J., Worsnop, D. R., Smith, J. N., and Laaksonen, A.: Bounce behavior of freshly nucleated biogenic secondary organic aerosol particles, Atmos. Chem. Phys., 11, 8759-8766, doi:10.5194/acp-11-8759-2011, 2011.

Voisin, D., Smith, J. N., Sakurai, H., McMurry, P. H., and Eisele, F. L.: Thermal desorption chemical ionization mass spectrometer for ultrafine particle chemical composition, Aerosol Sci. Technol., 37, 471-475, doi:10.1080/02786820300959, 2003.

Wang, L., Khalizov, A. F., Zheng, J., Xu, W., Ma, Y., Lal, V., and Zhang, R.: Atmospheric nanoparticles formed from heterogeneous reactions of organics, Nat. Geosci., 3, 238-242, doi:10.1038/ngeo778, 2010.

Wang, S. and Johnston, M. V.: Airborne nanoparticle characterization with a digital ion trap-reflectron time of flight mass spectrometer, Int. J. Mass Spectrom., 258, 50-57, doi:10.1016/j.ijms.2006.07.001, 2006.

Wang, S., Zordan, C. A., and Johnston, M. V.: Chemical characterization of individual, airborne sub-10-nm particles and molecules, Anal. Chem., 78, 1750-1754, doi:10.1021/ac0522431, 2006.

Weber, R. J., Marti, J. J., McMurry, P. H., Eisele, F. L., Tanner, D. J., and Jefferson, A.: Measurements of new particle formation and ultrafine particle growth rates at a clean continental site, J. Geophys. Res., 102, 4375, doi:10.1029/96JD03656, 1997. 
Westervelt, D. M., Pierce, J. R., Riipinen, I., Trivitayanurak, W., Hamed, A., Kulmala, M., Laaksonen, A., Decesari, S., and Adams, P. J.: Formation and growth of nucleated particles into cloud condensation nuclei: model-measurement comparison, Atmos. Chem. Phys., 13, 7645-7663, doi:10.5194/acp-13-76452013, 2013.

Westervelt, D. M., Pierce, J. R., and Adams, P. J.: Analysis of feedbacks between nucleation rate, survival probability and cloud condensation nuclei formation, Atmos. Chem. Phys., 14, 55775597, doi:10.5194/acp-14-5577-2014, 2014.

Wexler, A. S. and Clegg, S. L.: Atmospheric aerosol models for systems including the ions $\mathrm{H}+, \mathrm{NH} 4+, \mathrm{Na}+, \mathrm{SO} 42-$, NO3-, $\mathrm{Cl}-, \mathrm{Br}-$, and H2O, J. Geophys. Res.-Atmos., 107, ACH-14-1ACH-14-14, doi:10.1029/2001JD000451, 2002.

Winkler, P. M., Ortega, J., Karl, T., Cappellin, L., Friedli, H. R., Barsanti, K., McMurry, P. H., and Smith, J. N.: Identification of the biogenic compounds responsible for sizedependent nanoparticle growth, Geophys. Res. Lett., 39, doi:10.1029/2012GL053253, 2012.

Xu, L., Suresh, S., Guo, H., Weber, R. J., and Ng, N. L.: Aerosol characterization over the southeastern United States using highresolution aerosol mass spectrometry: spatial and seasonal variation of aerosol composition and sources with a focus on organic nitrates, Atmos. Chem. Phys., 15, 7307-7336, doi:10.5194/acp15-7307-2015, 2015.

Yli-Juuti, T., Barsanti, K., Hildebrandt Ruiz, L., Kieloaho, A.J., Makkonen, U., Petäjä, T., Ruuskanen, T., Kulmala, M., and Riipinen, I.: Model for acid-base chemistry in nanoparticle growth (MABNAG), Atmos. Chem. Phys., 13, 12507-12524, doi:10.5194/acp-13-12507-2013, 2013.
Yu, F.: A secondary organic aerosol formation model considering successive oxidation aging and kinetic condensation of organic compounds: global scale implications, Atmos. Chem. Phys., 11, 1083-1099, doi:10.5194/acp-11-1083-2011, 2011.

Yu, H., Ortega, J., Smith, J. N., Guenther, A. B., Kanawade, V. P., You, Y., Liu, Y., Hosman, K., Karl, T., Seco, R., Geron, C., Pallardy, S. G., Gu, L., Mikkilä, J., and Lee, S.-H.: New Particle Formation and Growth in an Isoprene-Dominated Ozark Forest: From Sub-5 nm to CCN-Active Sizes, Aerosol Sci. Technol., 6826, 1285-1298, doi:10.1080/02786826.2014.984801, 2014.

Zaveri, R. A., Easter, R. C., Fast, J. D., and Peters, L. K.: Model for Simulating Aerosol Interactions and Chemistry (MOSAIC), J. Geophys. Res., 113, D13204, doi:10.1029/2007JD008782, 2008.

Zhang, R., Khalizov, A., Wang, L., Hu, M., and Xu, W.: Nucleation and growth of nanoparticles in the atmosphere, Chem. Rev., 112, 1957-2011, doi:10.1021/cr2001756, 2012a.

Zhang, X., Pandis, S. N., and Seinfeld, J. H.: Diffusion-Limited Versus Quasi-Equilibrium Aerosol Growth, Aerosol Sci. Technol., 46, 874-885, doi:10.1080/02786826.2012.679344, 2012b.

Zhao, J., Eisele, F. L., Titcombe, M., Kuang, C., and McMurry, P. H.: Chemical ionization mass spectrometric measurements of atmospheric neutral clusters using the cluster-CIMS, J. Geophys. Res., 115, D08205, doi:10.1029/2009jd012606, 2010.

Zhao, J., Ortega, J., Chen, M., McMurry, P. H., and Smith, J. N.: Dependence of particle nucleation and growth on high-molecularweight gas-phase products during ozonolysis of $\alpha$-pinene, Atmos. Chem. Phys., 13, 7631-7644, doi:10.5194/acp-13-76312013, 2013. 